NBER WORKING PAPER SERIES

\title{
AGGREGATE IDIOSYNCRATIC VOLATILITY
}

\author{
Geert Bekaert \\ Robert J. Hodrick \\ Xiaoyan Zhang \\ Working Paper 16058 \\ http://www.nber.org/papers/w16058
NATIONAL BUREAU OF ECONOMIC RESEARCH
1050 Massachusetts Avenue
Cambridge, MA 02138
June 2010

A previous version of this article circulated under the title "Is there a trend in idiosyncratic volatility?" We are very grateful to Tim Vogelsang who provided code for the linear time trend test. We have benefited from the comments of the referee and the editor (Stephen Brown) as well as from discussions with Lieven Baele, Ian Cooper, Rob Engle, Cheol Eun, Mardi Dungey, Chris Jones, Federico Nardari, Tim Simin, Geert Rouwenhorst, Tim Simin and from presentations at the AFA in San Francisco, the EFA in Bergen, Cornell, Rutgers, NYU, the Wharton International Finance Workshop, the Queen's University International Finance Conference, University of Toronto, University of Washington, University of Colorado, Boston College, Purdue, University of Texas at Dallas, Indiana University, University of California at Riverside, University of Houston, and Hong Kong University of Science and Technology. The authors thank NETSPAR for financial support. The views expressed herein are those of the authors and do not necessarily reflect the views of the National Bureau of Economic Research.

NBER working papers are circulated for discussion and comment purposes. They have not been peerreviewed or been subject to the review by the NBER Board of Directors that accompanies official NBER publications.

(C) 2010 by Geert Bekaert, Robert J. Hodrick, and Xiaoyan Zhang. All rights reserved. Short sections of text, not to exceed two paragraphs, may be quoted without explicit permission provided that full credit, including $(\mathrm{C}$ notice, is given to the source. 
Aggregate Idiosyncratic Volatility

Geert Bekaert, Robert J. Hodrick, and Xiaoyan Zhang

NBER Working Paper No. 16058

June 2010, Revised July 2011

JEL No. G12

\begin{abstract}
$\underline{\text { ABSTRACT }}$
We examine aggregate idiosyncratic volatility in 23 developed equity markets, measured using various methodologies, and we find no evidence of upward trends when we extend the sample until 2008. Instead, idiosyncratic volatility appears to be well described by a stationary autoregressive process that occasionally switches into a higher-variance regime that has relatively short duration. We also document that idiosyncratic volatility is highly correlated across countries. Finally, we examine the determinants of the time-variation in idiosyncratic volatility. In most specifications, the bulk of idiosyncratic volatility can be explained by a growth opportunity proxy, total (U.S.) market volatility, and in most but not all specifications, the variance premium, a business cycle sensitive risk indicator.
\end{abstract}

\author{
Geert Bekaert \\ Graduate School of Business \\ Columbia University \\ 3022 Broadway, 411 Uris Hall \\ New York, NY 10027 \\ and NBER \\ gb241@columbia.edu \\ Robert J. Hodrick \\ Graduate School of Business \\ Columbia University \\ 3022 Broadway \\ New York, NY 10027 \\ and NBER \\ rh169@columbia.edu
}

Xiaoyan Zhang

Johnson Graduate School of Management

366 Sage Hall

Cornell University

Ithaca, NY 14853

xz69@cornell.edu 


\section{Introduction}

Much recent research in finance has focused on idiosyncratic volatility ${ }^{1}$. Morck, Yeung and $\mathrm{Yu}$ (2000) suggested that the relative importance of idiosyncratic variance in total variance is a measure of market efficiency. The level of idiosyncratic volatility clearly is also an important input in the study of diversification benefits. Here, a growing literature attempts to explain the trend in idiosyncratic volatility first documented by Campbell, Lettau, Malkiel and Xu (2001), CLMX henceforth. Aktas, de Bodt and Cousin (2007) and Kothari and Warner (2004) study how this permanent increase affects the use of one of the most powerful empirical techniques in finance, the event study. Comin and Mulani (2006) examine how and why trends in the macro-economy seem to diverge from the "micro-trend". ${ }^{2}$

Our first contribution is to expand the study of the time-series behavior of aggregate idiosyncratic volatility to international data. This is not only important for purely statistical reasons, but it also helps to inform the debate about the determinants of the time-variation in idiosyncratic volatility. Our results are in fact startling: there are no significant trends in idiosyncratic volatility for non-U.S. developed countries. For the 1980-2008 sample, we estimate negative trend coefficients for 9 countries. For the full sample of U.S. data, we also find no support for the hypothesis of a trend in idiosyncratic volatility. This finding is consistent with the results in Brandt, Brav, Graham and Kumar (2010) who argue that the increase in idiosyncratic volatility in the 1990s was temporary ${ }^{3}$.

\footnotetext{
${ }^{1}$ We use the terms volatility and variance interchangeably.

${ }^{2}$ A rapidly growing literature considers the pricing of idiosyncratic risk. See Ang, Hodrick, Xing and Zhang $(2006,2009)$ and the references therein. We do not address expected return issues here.

${ }^{3}$ In a study focusing on the predictive relation between idiosyncratic volatilities and aggregate returns, Guo
} 
The results in CLMX appear quite robust to alternative methodologies to compute idiosyncratic volatility and to the use of alternative trend tests within their sample. Nevertheless, we show that the test results are sensitive to the sample period: ending the sample in the 19881998 decade is key to finding a trend. Of course, when a time series exhibits apparent time trends over part of its sample, it is likely characterized by near non-stationary-behavior. We show that average idiosyncratic volatility is well described by a relatively stable autoregressive process that occasionally switches into a higher-variance regime that has relatively low duration. Hence, our evidence does not support permanent changes in idiosyncratic volatility. We also document a new empirical fact: idiosyncratic volatility is highly correlated across countries, and these correlations have increased over time.

Our findings provide a challenge for some of the explanations for the "trend" in aggregate idiosyncratic variance proposed in the literature. Successful theories should capture the low frequency changes in the idiosyncratic volatility time series data and the correlation across countries. The literature has identified roughly three types of determinants. A first set focuses on the changing composition of stock market indices. Fink, Fink, Grullon and Weston (2010) ascribe the trend to the increasing propensity of firms to issue public equity at an earlier stage in their life cycle, while Brown and Kapadia (2007) argue that the trending behavior is due to the listings of more riskier firms over the years. The second and largest set of explanations focuses on what we call "corporate variables": firm-specific characteristics that ultimately determine idiosyncratic cash flow variability. These articles include Guo and Savakis (2007) (changes in and Savickas (2008) point out there is no significant trend in idiosyncratic volatility for the G7 countries, and that these volatilities are highly correlated with US idiosyncratic volatility. 
the investment opportunity set), Cao, Simin and Zhao (2007) (growth options), Comin and Philippon (2005) (research and development spending and access to external financing), and Wei and Zhang (2008) (earnings quality). Gaspar and Massa (2006) and Irvine and Pontiff (2008) point to increasingly competitive product markets as a potential "deeper" explanation of increased idiosyncratic cash flow variability. Financial development has made stock markets more informative and increased idiosyncratic variability, relative to total market variability (see Chun, Kim, Morck and Yeung 2007). The third set of articles is more "behavioral" in nature and relies on changes in the degree of market inefficiency to generate changes in idiosyncratic variability. Xu and Malkiel (2003) and Bennett, Sias, and Starks (2003) ascribe the rise in idiosyncratic volatility to an increase in institutional ownership, and especially the increased preferences of institutions for small stocks. Brandt, et al. (2010) attribute the temporary increase to "speculative behavior", as evidenced by retail traders in the Internet Bubble. They find that the period between 1926 and 1933 exhibited a similar temporary increase in idiosyncratic volatility, which they also ascribe to speculative behavior.

Our time series characterization of idiosyncratic volatility immediately excludes certain variables as important determinants. For example, because institutional ownership exhibits a clear trend, it cannot fully explain the evidence. However, it is possible that the propensity to issue public equity is not trending upward but also shows regime-switching behavior. The final part of our article runs horse races between the various determinants, in addition to exploring the links between idiosyncratic volatility and market volatility and the business cycle, which have not been studied before. This turns out to be an important omission: together with growth opportunities, market volatility and a cyclical risk aversion indicator appear to drive most of 
the variation in idiosyncratic volatility, both in the U.S. and internationally.

The rest of the article is organized as follows. Section 2 describes the data. Section 3 contains the main results for trend tests. Section 4 characterizes the time-series properties of aggregate idiosyncratic volatility. Section 5 examines the explanatory power of a large number of potential determinants. In the conclusions, we summarize our findings.

\section{Data}

\subsection{The U.S. Sample}

In order to replicate and extend the CLMX study, we first collect daily U.S. stock returns between 1964 and 2008 from CRSP. We calculate excess returns by subtracting the U.S. T-bill rate, which is obtained from the CRSP riskfree file. We calculate the idiosyncratic volatility of a firm's return using two methods. First, we compute the idiosyncratic variance as in CLMX. The model for individual firm $j$ for day $t$ is:

$$
R_{j, t}=I N D_{J, t}+u_{j, t}^{C L M X}
$$

Here, $I N D_{J, t}$ is the return on a corresponding industry portfolio $J$ to which firm $j$ belongs. ${ }^{4}$ The firm's idiosyncratic variance is then the variance of the residual $u_{j, t}^{C L M X}$, computed with one month of daily return data. Value-weighting the firm-level idiosyncratic variances produces the CLMX aggregate idiosyncratic variance. That is,

$$
\sigma_{C L M X, m}^{2}=\sum_{j=1}^{N} w_{j, m} \sigma^{2}\left(u_{j, t}^{C L M X}\right),
$$

\footnotetext{
${ }^{4}$ We use 26 industries by merging SIC codes for U.S. firms and FTSE industry codes for foreign firms, as in Bekaert, Hodrick and Zhang (2009).
} 
where day $t$ belongs to month $m$. Here the weight $w_{j, m}$ is computed using firm $j$ 's previous month market capitalization, and $N$ is the number of firms. Implicitly, CLMX assume that systematic risks are captured by the industry return and that firms have unit betas with respect to the industry to which they belong.

Bekaert, Hodrick and Zhang (2009), BHZ henceforth, show that the unit beta restrictions in the CLMX approach severely limit the factor model's ability to match stock return comovements. We therefore also consider the Fama-French (1996) model, which fits stock return comovements better:

$$
R_{j, t}=b_{0, j, m}+b_{1, j, m} M K T_{t}+b_{2, j, m} S M B_{t}+b_{3, j, m} H M L_{t}+u_{j, t}^{F F},
$$

where day $t$ belongs to month $m$. Here, the variable $M K T$ represents the excess return on the market portfolio, $S M B$ is the size factor, and $H M L$ is the value factor. This model is more in line with standard methods to correct for systematic risk. Data on the Fama-French factors are obtained from Kenneth French's website. To allow the betas to vary through time, we re-estimate the model every month with daily data. The idiosyncratic variance for firm $j$ is the variance of the residual of the regression, that is, $\sigma^{2}\left(u_{j, t}^{F F}\right)$. We again compute the idiosyncratic variance at the country level using value weighting:

$$
\sigma_{F F, m}^{2}=\sum_{j=1}^{N} w_{j, m} \sigma^{2}\left(u_{j, t}^{F F}\right),
$$

where day $t$ belongs to month $m$. 


\subsection{The Developed Countries Sample}

We study daily excess returns for individual firms from 23 developed markets, including the U.S. The sample runs from 1980 to 2008. All returns are U.S. dollar denominated. Our selection of developed countries matches the countries currently in the Morgan Stanley Developed Country Index. Data for the U.S. are from Compustat and CRSP; data for the other countries are from DataStream. In the DataStream data, it is likely that new and small firms are increasingly more represented in the sample. This could bias our tests towards finding a trend. We estimate domestic models, such as the CLMX model in equation (1) and the FF model in equation (3), for each developed country, where the industry, size and value factors are constructed in the corresponding national market. In section 3.2, we conduct a robustness check using a model which explicitly allows for both global and local factors.

\subsection{Summary Statistics}

Table 1 presents summary statistics for the time-series of annualized idiosyncratic variances. Panel A focuses on the long U.S. sample where we have 540 monthly observations. The mean of the annualized CLMX idiosyncratic variance is 0.0800 with a time-series standard deviation of 0.0592, and the mean of the annualized Fama-French idiosyncratic variance is 0.0697 with a time-series standard deviation of 0.0484 . Hence, the Fama-French risk adjustments lower both the mean and the volatility of the idiosyncratic variance series relative to the CLMX-idiosyncratic variance. The correlation between the two idiosyncratic variance series is nonetheless $98 \%$.

Panel B of Table 1 reports idiosyncratic variance statistics computed for 23 countries, using 
the CLMX model on the left and the FF model on the right. Among the G7 countries, Japan, the U.S. and Canada have the highest idiosyncratic variances, and Germany and the U.K. have the lowest idiosyncratic variances. Among the other countries, the idiosyncratic volatility is the highest for Greece at 0.0901 when using the CLMX model, and it is 0.0798 when using the FF model. The idiosyncratic variance is the lowest for Switzerland at around $0.03 .^{5}$

Panel C of Table 1 presents correlations among the idiosyncratic variances of the G7 countries. No matter which model we use, the idiosyncratic variances are highly correlated across countries. Using Pearson's test, we find that all correlation coefficients are significant at the $5 \%$ level. This is an important new fact, as it suggests that there might be a common driving force for idiosyncratic variances across countries.

Figure 1 presents the time-series of the various idiosyncratic variance measures. There are periods of temporarily higher volatility in the U.S., including 1970, 1974, 1987, a longer-lasting increase in 1998, which seems to reverse after 2003, and the recent crisis period. In other countries, the most obvious high variance periods are again 1998-2001, and the recent crisis period. However, periods of higher volatility are apparent earlier in the sample as well; for instance, around 1987 for a number of countries and in the early 1980s, for France and Italy.

\footnotetext{
${ }^{5}$ Bartram, Brown, and Stulz (2009) find that a typical U.S. firm has higher idiosyncratic risk than a comparable foreign firm and explore the cross-sectional determinants of this difference.
} 


\section{Trend Tests}

\subsection{Main Results}

One of the main results in CLMX is that the average idiosyncratic variance in the U.S. exhibits a positive time trend. To formally test for trends, we follow CLMX and use Vogelsang's (1998) linear time trend test. The benchmark model is

$$
y_{t}=b_{0}+b_{1} t+u_{t}
$$

where $y_{t}$ is the variable of interest, and $t$ is a linear time trend. We use the PS1 test in Vogelsang (1998) to test $b_{1}=0$. The conditions on the error terms under which the distributions for the test statistics are derived are quite weak and accommodate most covariance stationary processes (such as regime switching models) and even I(1) processes. In all of the ensuing tables, we report the trend coefficient, the t-statistic and the $5 \%$ critical value derived in Vogelsang (1998) (for a two-sided test). In addition, Bunzel and Vogelsang (2005) develop a test that retains the good size properties of the PS1 test, but it has better power (both asymptotically and in finite samples). We denote this test with a "dan" subscript, as the test uses a "Daniell kernel" to non-parametrically estimate the error variance needed in the test. In fact, tests based on this kernel maximize power among a wide range of kernels. We use an $\mathrm{AR}(1)$ model to prewhiten the data because Bunzel and Vogelsang (2005) show that pre-whitening improves the finite sample properties of the test. Vogelsang generously provided us with the code for both the t-ps1 and t-dan tests.

Table 2 reports the trend test results. Panel A considers the same U.S. sample as in CLMX, which is 1964-1997, and we find a significant trend in the idiosyncratic variance, no matter 
whether we use the FF or CLMX model. Panel B includes 11 more years of data, and the idiosyncratic variance does not display a significant trend in any of the cases. Clearly, the trend documented in CLMX is time-period dependent. Since the pre-whitened and non-pre-whitened results are very similar, we only report the pre-whitened results for the t-dan test in later sections.

Panel $\mathrm{C}$ of Table 2 reports trend test results for the 23 developed countries, country by country. Using $\sigma_{C L M X}^{2}$, we fail to detect a significant positive time trend for all countries, either using the t-dan test or the t-ps1 test. France, Italy, Australia, Belgium, Finland, Greece, New Zealand, Portugal and Spain have negative trend coefficients, which are significantly different from zero for Italy and Portugal. Because the results for $\sigma_{F F}^{2}$ are entirely similar, we do not report them to save space. In summary, positive trending behavior is simply not visible in idiosyncratic volatility across the developed world.

\subsection{Robustness and Further Tests}

Whereas the two models deliver highly correlated idiosyncratic variance series, the dependence of the idiosyncratic variance on a risk model remains an issue of concern. Here we consider several robustness checks. First, we compute the model free measure proposed by Bali, Cakici and Levy (2008, BCL hereafter), $\sigma_{B C L}^{2}$ henceforth:

$$
\sigma_{B C L, m}^{2}=\left(\sum_{j=1}^{N} w_{j, m} \sigma\left(R_{j, t}\right)\right)^{2}-\sigma^{2}\left(R_{M K T, t}\right) .
$$

Here the various $\sigma^{\prime} s$ are simply the monthly volatilities of individual stocks and therefore the measure does not require the computation of any risk exposures. Intuitively, the measure subtracts systematic risk, measured by the market variance, from the square of the average 
volatility. When all risk is systematic (that is, when stocks are perfectly or very highly correlated), the measure goes to zero. With equal standard deviations across stocks, the measure equals the $\sigma_{C L M X}^{2}$ measure, but the BCL measure will generally be smaller than the CLMX measure, with the difference increasing in the cross-sectional dispersion of individual volatilities (see BCL).

Table 2 also contains trend estimates using the BCL measure. The BCL measure delivers exactly the same inference as our other measures do. There is a trend in US idiosyncratic variance over the CLMX sample, but not over the full sample, and there are no trends in international data, except for a negative trend in Portugal.

Another drawback of the models used so far is that they may not adequately capture global risks. In the Online Appendix, we produce results using the risk model advocated by BHZ (2009). The model has global and local Fama French factors, and is estimated using weekly data every six months. Nevertheless, the results remain similar, and we again fail to detect a significant time trend for any country.

A final concern is that the trend results are due to a small subset of stocks. For example, one of the reasons suggested for the trend in aggregate idiosyncratic variance is that small firms may have sought public funding at an earlier stage in their life cycle than before (see Fink, Fink, Grullon and Weston 2010). This would imply that small firms would have a large effect on the results, which is less likely with the value-weighted measures we consider than it is with equally weighted measures. In the Online Appendix, we consider trend tests for equally weighted idiosyncratic variances for the US. We do not find a significant trend, even for the 1964-1997 period (consistent with CLMX in fact). 
Various authors have proposed looking at sub classes of stocks and we come back to such explanations for trend behavior in Section 5 . Here we follow BCL in considering tests for NYSE and NASDAQ stocks, large and small stocks, old and young stocks and high price and low price stocks. BCL find weaker trends for NYSE stocks and for older stocks. The Online Appendix shows that for our expanded sample, there are no meaningful differences in trend results for any of these sub-groups.

\section{Characterizing the Dynamics of Idiosyncratic Volatility}

The results in Section 3 fail to support the presence of a gradual permanent increase in idiosyncratic variances, as captured by a deterministic time trend. Other forms of nonstationary behavior remain a possibility, however. We first examine the presence of stochastic trends. Using the Dickey and Fuller (1979) and Phillips and Perron (1988) tests, we invariably reject the null hypothesis of a unit root, consistent with the evidence in Guo and Savickas (2008).

We also examine models with structural breaks, adopting the methodology in Bai and Perron (1998). For all countries, we identify a relatively large number of breaks, with the break dates highly correlated across countries. In particular, the tests consistently reveal the end of 1997/1998 and 2001/2002 as break dates, thus selecting a temporary period of higher idiosyncratic volatility associated with what many economists have called the Internet or Tech Bubble. For the U.S. long sample, the BIC selection criterion is minimized at 5 (3) breaks, when the minimum sub-sample size is $5 \%(15 \%)$ of the total sample. Generally, the "break tests" identify periods of temporarily higher volatility that may occur more than once during the 
sample period. We consequently estimate a regime-switching model to capture such behavior.

\subsection{Country Specific Regime Switching Model}

\subsubsection{The Model}

Let $y_{t}$ represent the original aggregate idiosyncratic variance. Following Hamilton (1994), we allow $y_{t}$ to follow an $\mathrm{AR}(1)$ model where all parameters can take on one of two values, depending on the realization of a discrete regime variable, $s_{t}$. The regime variable follows a Markov Chain with constant transition probabilities. Let the current regime be indexed by $i$.

$$
y_{t}=\left(1-b_{i}\right) \mu_{i}+b_{i} y_{t-1}+\sigma_{i} e_{t}, \quad i \in\{1,2\} .
$$

with $e_{t} \sim N(0,1)$. In estimation, we force regime $1(2)$ to be the lower (higher) idiosyncratic variance regime, and the mean levels of idiosyncratic variances in both regimes to be nonnegative, that is, we constrain $\mu_{2}>\mu_{1}>0$.

The transition probability matrix, $\Phi$, is $2 \times 2$, where each probability represents $P\left[s_{t}=\right.$ $\left.i \mid s_{t-1}=j\right]$, with $i, j \in\{1,2\}:$

$$
\Phi=\left(\begin{array}{cc}
p 11 & 1-p 11 \\
1-p 22 & p 22
\end{array}\right)
$$

The model is parsimonious, featuring only 8 parameters, $\left\{\mu_{1}, \mu_{2}, b_{1}, b_{2}, \sigma_{1}, \sigma_{2}, p 11, p 22\right\}$.

\subsubsection{Estimation Results}

In Table 3 (left panel), we report the estimation results for both $\sigma_{C L M X}^{2}$ and $\sigma_{F F}^{2}$ for the long U.S. sample. The standard errors are computed using the robust White (1980) covariance 
matrix. The annualized idiosyncratic variance level for regime $1, \mu_{1}$, is 0.062 for $\sigma_{C L M X}^{2}$, and 0.055 for $\sigma_{F F}^{2}$, but the level increases dramatically for regime 2 , with $\mu_{2}$ equal to 0.181 for $\sigma_{C L M X}^{2}$ and 0.155 for $\sigma_{F F}^{2}$. Using a Wald test, the level differences between the two regimes are highly statistically significant. It seems likely that a regime with high mean volatility also has high innovation volatility, and that is indeed what we find. Regime 2 has much higher volatility than regime 1 , as $\sigma_{1}$ is 0.011 but $\sigma_{2}$ is 0.082 for $\sigma_{C L M X}^{2}$, with similar results when we use $\sigma_{F F}^{2}$. It is also typical for a high-variance regime to show more mean-reverting behavior, and we also find this to be the case for the point estimates for both $\sigma_{C L M X}^{2}$ and $\sigma_{F F}^{2}$. The difference between the two autocorrelation coefficients is statistically significant.

Figure 2 presents time-series of the smoothed probabilities of being in regime 2, which are computed using information from the whole time-series. The high-variance regime is a shortlived regime, but it occurs several times during the sample period with some consistency across the two risk models. High variance episodes that occur in both cases include 1970, 1974, 1987, 1996, 1998-2002 and 2007-2008. If we define $y_{t}$ to be in regime 2 if the probability of being in regime 2 is higher than 0.5 , and vice versa for regime 1 , then there are 13(11) regime switches over the 45 year sample for $\sigma_{C L M X}^{2}\left(\sigma_{F F}^{2}\right)$, and $y_{t}$ is in regime $214 \%$ of the time. On average, regime 2 lasts about 10 to 11 months.

It is not difficult to give some economic content to the regimes. The shaded areas in Figure 2 are NBER recessions. Clearly, the high-level idiosyncratic variance regimes mostly coincide with periods of recessions, although recessions are neither necessary nor sufficient to have a high volatility regime. It is well-known that market volatility tends to be high in recessions (see Schwert, 1989). We also find that our high idiosyncratic variance regimes coincide with 
market volatility being about twice as high as in normal regimes. We come back to this finding in a later section. The link between high idiosyncratic variance regimes and recessions appears stronger for $\sigma_{C L M X}^{2}$ than for $\sigma_{F F}^{2}$.

The results for the shorter sample period of G7 countries are in the right panel of Table 3 . The levels of idiosyncratic variances differ across countries, but not dramatically. In the low variance regime, the means vary between 0.033 (Germany) and 0.072 (Japan). For the high variance regime, the means vary between 0.121 (Germany) and 0.198 (U.S.). The persistence parameters are mostly lower in regime 2, but not significantly in Japan, the U.K. and the U.S. The results using the FF model are very similar, and we do not report them to save space. In the Figure A1 of the Online Appendix, the smoothed probabilities in regime 2 (high volatility regime) using the CLMX model are presented. Essentially, the idiosyncratic variances of all 6 countries are mostly in regime 2 around 1997 to 2002 and back again in the recent crisis period. They are also likely to be in regime 2 around the $1987 \mathrm{crash}$. Most countries experience additional transitions into the higher variance regime.

We also consider an extensive set of specification tests for the regime switching model for all countries, comparing it to a number of simpler models and also to models applied to the logarithm of the variance. The regime switching models discussed here outperform the alternative models and most specification tests fail to reject, with the model performing least well for Canada, Germany and the UK. The Online Appendix describes the specification tests and contains detailed results. 


\subsubsection{Regime Switches and the CLMX Results}

These results help us interpret the CLMX finding of a trend. Essentially, the idiosyncratic variance process does not exhibit a trend, but it exhibits covariance stationary behavior with regime switching. Of course, trend tests, despite having good finite sample properties, may perform much worse in an environment that starts the sample in a low level regime and ends in a high level regime.

The CLMX sample starts during a "normal" idiosyncratic variance regime in the 1960's and ends in 1997. While 1997 is not classified as a high variance regime, it is in the middle of a period with frequent shifts into the high variance regime. As Figure 2 shows, the probability that $\sigma_{C L M X}^{2}$ is in the high-level, high-variance regime increased briefly around October $1987^{6}$, increases slightly several times in the following years, before increasing substantially but briefly in June and July of 1996. In April 1998, a longer lasting high variance regime starts. Conditioning on such a sample selection, a trend test may be more likely to reject than the asymptotic size of the test indicates.

To see the effect more concretely, Figure 3 shows the recursively computed values of the t-dan test, starting the sample in 1964:01 but varying the end point between 1970:04 and the end of the sample (2008:12). The date 1970:04 is not chosen arbitrarily, it is in the first high variance regime selected by the regime switching model, and it is striking that the trend test would have rejected when dates around that time were chosen as sample end points. The trigger date for finding an upward trend was the crash of October 1987, and an upward trend

\footnotetext{
${ }^{6}$ Schwert (1990) shows how stock market volatility, during and after the crash, was very unusual but returned to normal levels relatively quickly.
} 
would have been found all the way until 2000:4. Using the less powerful t-ps1 test, actually employed by CLMX, this period of "false rejections" would have lasted about two years less long. This analysis has two important implications: first, the level of idiosyncratic volatility has been high over the 1990s; second, if the time-series starts in a low volatility period, and ends in a high volatility period, the trend test tends to be significant, even though the time-series follows an overall stationary process. The recent data reinforce the regime-switching nature of the idiosyncratic variance process. By 2004, the level of idiosyncratic variance had dropped back to pre 1970 levels, only to rise starkly (and most likely temporarily) in the financial crisis that started in 2008 .

\subsection{Commonality in Idiosyncratic Volatilities}

The fact that idiosyncratic volatility has a large common component across countries deserves further scrutiny. This fact may have implications for the analysis of issues such as international diversification and contagion. Table 4 reports the correlations of the aggregate idiosyncratic variances in the G7 countries with respect to the aggregate U.S. idiosyncratic variance. Across the panels, the correlations with the U.S. vary between 0.20 (Italy) and 0.81 (UK). Table 4 also shows these correlations over the first and second halves of the sample. The increase in the correlation with the U.S. over time is remarkable.

It is possible that the phenomenon is also related to the regime switching behavior of idiosyncratic variances. In the last two columns of the table, we report the bivariate correlations with the U.S., conditioning on the idiosyncratic variance in the U.S. being either in the low level/low variance or high level/high variance regime. Perhaps not surprisingly, we find that 
the correlations are generally higher in the high-level/high variance regime ${ }^{7}$.

Because a missing common risk factor is a potential explanation of the commonality in idiosyncratic variances, we verified that our results are robust to using the international factor model with local and global factor mentioned in section 3.2. BHZ (2009) show that the idiosyncratic return correlations of country portfolios, computed using this risk model, are essentially zero. Using the BHZ risk model to compute idiosyncratic variances, the equally weighted correlation between the idiosyncratic variances of the G7 countries is $57 \%$ over the whole sample; $24 \%$ over the 1980-1994 period, but $75 \%$ over the $1995-2008$ period.

\section{Determinants of Idiosyncratic Volatility Dynamics}

Section 4 documents that idiosyncratic variances follow a stationary regime switching process, characterized by relatively low frequency changes in regime, in which they become temporarily higher, more variable, and more mean-reverting. These patterns are apparent in all countries. Moreover, there is a strong common component in idiosyncratic variances across countries that has increased in importance over time. These facts have significant implications for the rapidly growing literature trying to explain the time variation in idiosyncratic volatility.

In this section, we attempt to determine which prevailing explanation best fits the time

\footnotetext{
${ }^{7}$ In a previous version of the article, we actually estimated a joint regime-switching model over the G7 countries, where the U.S. regime variable functions as the standard regime variable and the regime variables in other countries depend on the U.S. variable. Results are available upon request. The joint model shows that when the U.S. is in the high level/high variance regime, the other G7 countries are more likely to be in this regime as well.
} 
series movements of idiosyncratic variances in the U.S. and in other countries. Because we have more data available in the U.S., we start there in section 5.1. Table 5 lists all the independent variables we use in the analysis and the acronyms we assign to them.

We distinguish three different types of variables: variables affecting changes in the index composition, "corporate" variables correlated with cash flow volatility, and finally, business cycle variables and market wide volatility, a category new to this literature. The first three sub-sections in 5.1 discuss these three groups of variables in more detail. Section 5.1.4 runs a statistical horse race to determine which variables best capture the time series variation in U.S. aggregate idiosyncratic volatility. Section 5.1.5 then examines whether the determinants can account for the time series behavior discovered in section 4. Specifically, we assess whether accounting for these determinants leads to residuals that are well-behaved and no longer exhibit regime switching behavior. In Panel B of Table 5, we list the variables that are available internationally, which is a subset of the variables available for the U.S. Section 5.2 then conducts an analysis of the determinants of aggregate idiosyncratic volatility in the G7 countries. Given the more limited nature of our data, this analysis should be viewed as a preliminary first look at the data.

\subsection{Analysis of U.S. Data}

Most of the literature has focused on U.S. data. Our general approach is to regress the idiosyncratic variance time series on a set of explanatory variables, mostly constructed exactly as in the extant literature. The reported standard errors are heteroskedasticity consistent and always allow for 12 Newey-West (1987) lags. 


\subsubsection{Index Composition and Behavioral Variables}

One possible explanation offered for a potential increase in idiosyncratic variances over time is that the composition of the index has changed towards younger, more volatile firms. Fink, Fink, Grullon and Weston (2010) show that the age of the typical firm at its IPO date has fallen dramatically from nearly 40 years old in the early 1960s to less than 5 years old by the late 1990s. Since younger firms tend to be more volatile, this systematic decline in the average age of IPOs, combined with the increasing number of firms going public over the last 30 years, may have caused a significant increase in idiosyncratic risk. Brown and Kapadia (2007) also ascribe increases in firm-specific risk to new listings by riskier companies (although not necessarily solely related to age), whereas $\mathrm{Xu}$ and Malkiel (2003) argue that the increase can be partly attributed to the increasing prominence of the NASDAQ market. We proxy for the age effect using the percentage of market cap of firms which are less than 10 years old since foundation (pyoung).

A related possibility is that small capitalization stocks, which tend to have higher idiosyncratic volatilities, have become relatively more important (see Bennett, Sias and Starks, 2003). It is possible such a trend is a fundamental response to markets becoming more efficient over time, making it possible for smaller firms to list and be priced efficiently. Bennett, Sias and Starks (2003) explicitly ascribe the trend to institutional investors becoming more actively interested in small capitalization stocks over time, which could increase trading in these stocks and make these markets more liquid and consequently more efficient, thereby providing higher valuations. Xu and Malkiel (2003) also argue that an increase in institutional ownership is associated with higher idiosyncratic volatility. To measure the effect of the relative impor- 
tance of small capitalization firms on idiosyncratic variability, we use the proportion of market capitalization represented by the smallest $25 \%$ of all listed firms (psmall).

Such an explanation is hard to distinguish from certain "behavioral explanations". Brandt, Brav, Graham and Kumar (2010) ascribe episodic shifts in idiosyncratic volatility to speculative behavior. While difficult to measure, they argue that the 1990s episode of high and increasing idiosyncratic volatility is concentrated primarily in firms with low stock prices and limited institutional ownership. Their explanation is hence quite different, and almost contradictory to the arguments made by Bennett, Sias and Starks (2003) and Xu and Malkiel (2003), but it nonetheless also gives a primary role to small stocks. We use two variables to imperfectly measure the "speculative trading" channel: the percentage of market cap of firms with a stock price lower than $\$ 5$ (plow), and the average turnover of firms with a stock price lower than $\$ 5$ (lowto).

More generally, retail investors can potentially act as noise traders and increase trading volume and volatility (see also Foucault, Sraer and Thesmar 2008). We also use a general measure of turnover, computed as total dollar volume over total market capitalization. A positive effect of turnover on volatility could also reflect increased turnover indicating a more developed, more efficient stock market, which in turn may be associated with higher idiosyncratic variability, see Jin and Myers $(2006)^{8}$.

The first column on the left hand side of Table 6 runs a regression of our CLMX measure of idiosyncratic variances onto the 5 variables described above. While the fraction of young firms

\footnotetext{
${ }^{8}$ Ferreira and Laux (2007) suggest corporate governance policy as a concrete channel promoting informational efficiency and higher idiosyncratic volatilty.
} 
is positively associated with aggregate idiosyncratic variability, the effect is not statistically significant. Both the proportions of small stocks and low priced stocks are negatively associated with aggregate idiosyncratic risk; with the effects significant at $10 \%$ level. The turnover in low priced stocks is negatively associated with idiosyncratic risk, yet overall turnover is positively associated with idiosyncratic risk. Neither effect is significant. In summary, the variables that provide some marginal explanatory power have the wrong sign. The $R^{2}$ of the regression is $35 \%$.

Introducing institutional ownership would help to distinguish the Bennett, Sias and Starks (2003) explanation from that of Brandt et al. (2010). Unfortunately, the fraction of shares owned by institutional investors is only available from 1981 onwards, eliminating 17 years from the sample period. Over this shorter sample period, institutional ownership is univariately positively related with idiosyncratic variability, but the coefficient is insignificantly different from zero. When we run a regression including our five other variables, the coefficient on institutional ownership becomes significantly negative, which is not consistent with the Bennett, Sias and Starks (2003) hypothesis. The results are somewhat hard to interpret, because institutional ownership is quite highly correlated with the 5 variables included in our analysis. In fact, these five variables explain $77 \%$ of the variation in institutional ownership. The fact that institutional ownership shows a clear upward trend also implies that it cannot really be a major factor driving the time-series variation in idiosyncratic variability. 


\subsubsection{Corporate variables}

Another part of the literature argues that the movements in idiosyncratic variances reflect fundamental (idiosyncratic) cash flow variability. The various articles differ in what aspects of fundamental variability they focus on, and how they interpret their results. Details about how to construct those variables can be found in the Online Appendix.

Building on theoretical work by Pastor and Veronesi (2003), Wei and Zhang (2006) argue that the upward trend in average stock return volatility is fully accounted for by a downward trend in the return-on-equity, indicating poorer earnings quality, and an upward trend in the volatility of the return-on-equity. To mimic their results, we create three empirical measures: the value-weighted average of the firm level return on equity (vwroe); the value-weighted firm level time-series variance of the return on equity computed using the past 12 quarters of data (vwvroe), and the cross-sectional variance of the return on equity at each point in time (cvroe).

Irvine and Pontiff (2008) attribute the increases in idiosyncratic return volatility to an increase in the idiosyncratic volatility of fundamental cash flows. We mimic their procedure to construct idiosyncratic cash flow volatility by first using a pooled AR(3) model for firms' earnings per share to create earnings innovations. Then, we define the cross-sectional variance of these innovations (veps). Both Irvine and Pontiff (2008) and Gaspar and Massa (2006) ascribe increases in fundamental idiosyncratic variability to more intense economy wide product competition. To proxy for "competition", we use a measure of industry turnover computed by first taking the percentage of market cap of firms entering and exiting the same industry at the industry level each month and then assigning this percentage to individual firms in the various industries. We use the value-weighted average of firm level industry turnover (indto). 
Cao, Simin and Zhao (2007) show that both the level and variance of corporate growth options are significantly related to idiosyncratic volatility. A bigger menu of projects presumably makes it easier for managers to increase idiosyncratic risk, which in turn increases equity value. We therefore use two variables: the value-weighted firm level market value of assets over the book value of assets (maba), as a proxy for growth options, and the value-weighted variance of the firm level's maba, vmaba, computed using data over the past three years. Finally, following the spirit of cvroe, we also compute the cross-sectional variance of maba at each point in time (cvmaba).

Finally, Chun, Kim, Morck and Yeung (2008) argue that a more intensive use of information technology and faster production growth created a wave of creative destruction, leading to higher idiosyncratic volatility. Chun et al. (2008) and Comin and Philippon (2008) therefore link idiosyncratic volatility to research intensity and spending. Following Comin and Mulani (2006), for each firm, we first compute its fiscal year R\&D expenditure divided by the quarter's total revenue. We then construct two R\&D related variables: the value-weighted average of the scaled R\&D expenditure ( $\mathrm{rd}$ ), and the cross-sectional variance of firm level scaled $R \& D$ expenditure (cvrd).

The second column of Table 6 reports results for a regression of CLMX idiosyncratic variance onto the 10 corporate variables described above. The total adjusted $R^{2}$ is $56 \%$, so these variables explain more of the time-series variation in aggregate idiosyncratic variances than the index variables did. We expect positive coefficients for all of these variables. Of course, many of them are highly correlated, causing some multicollinearity. Of the return on equity variables, only the level is significant. Both earnings per share variability and industry turnover are significant. In 
addition, the growth option variable, maba, and both research spending variables are significant, but the volatility of R\&D has a surprisingly negative effect on idiosyncratic volatility.

\subsubsection{Business Cycles and Market Wide Volatility}

This section examines a number of potential determinants that the extant literature has not yet considered, namely business cycle variables and aggregate market volatility. Business cycle variables could affect aggregate idiosyncratic variability through a variety of channels. A first channel is simply that recessions are associated with increases in macro-economic uncertainty, which in turn drives up both systematic and idiosyncratic risk. In principle, the corporate variables we have used so far should pick up this effect, but it is possible they do not, or do so imperfectly.

Another possibility is that there is discount rate volatility that somehow was missed in the systematic factor measurement and causes idiosyncratic volatility fluctuations that may even be correlated across countries. This could be a missing risk factor, or the functional form of systematic risk measurement could be incorrect (e.g. the true factor model is really

non-linear). For example, if aggregate stock return predictability reflects variation in discount rates, the evidence in Henkel, Martin and Nardari (2008) suggests it is concentrated in certain periods, particularly recessions.

We use 7 variables to analyze business cycle effects. The first variable is the variance premium, mvp, which is the difference between the square of the VIX index, an option based measure of the expected volatility in the stock market, and the actual physical expected variance of stock returns (see also Carr and Wu (2009)). We take this measure from Baele, Bekaert and 
Inghelbrecht (2010), who show that it is an important determinant of stock market volatility. Bollerslev, Tauchen and Zhou (2009) show that mvp is an important predictor of stock returns, and hence constitutes an aggregate discount rate factor. Bali and Hovakimian (2009) find a significant link between variance risk premiums and the cross-section of expected stock returns. Theoretically, a variance premium can arise through stochastic risk aversion and nonlinearities in fundamentals (see Bekaert and Engstrom (2009), and Drechschler and Yaron (2008)) or through Knightian uncertainty (see Drechschler (2009)). Next, the regime switching model indicated an important link between market volatility (mkttv) and idiosyncratic volatility. We use this variable as the second business cycle variable in the regression. Note that idiosyncratic and aggregate volatility need not be automatically correlated, as long as the index is sufficiently well-diversified ${ }^{9}$. We also include growth in industrial production variable, dip, computed as industrial production minus its own two year moving average. We include two market-driven indicators of business cycle conditions, the term spread (term) and the default spread (def). Default spreads have long been used to predict economic activity (see e.g. Harvey (1988)); and more recently, the links between default spreads and future economic activity have been explored, by Mueller (2009) and Gilchrist, Yankov and Zakrejsek (2009). We also use a survey measure of consumer confidence (confi), from the conference board.

The last business cycle variable, disp, is a measure of uncertainty about corporate profits.

\footnotetext{
${ }^{9}$ We actually checked the source of correlations between aggregate total and aggregate idiosyncratic variance for the G7 countries, by splitting up the aggregate total variance in two components, a variance component (which should converge to zero in well-diversified indices as the number of firms get large) and a systematic component (which only depends on covariances). We find that the bulk of the correlation is accounted for by the systematic component, with the lowest proportions being $88 \%$ for Germany and Italy.
} 
The Survey of Professional Forecasters provides forecasts of nominal corporate profits for the previous quarter, the current quarter and the next four quarters. We calculate the forecasted growth rate for each forecaster by dividing the fourth quarter forecast by the current quarter forecast. We then compute the standard deviation across the different growth forecasts, obtaining a quarterly time series of the dispersion of the survey forecasts. ${ }^{10}$ This time series may be correlated with true macro-economic uncertainty and the variability of cash flows, or it may reflect different beliefs of different forecasters. In Anderson, Ghysels and Juergens (2009) these forecasts are used to construct a measure of Knightian uncertainty that should be a key factor driving the aggregate market risk premium.

The 7 business cycle variables explain $57 \%$ of the total variation in aggregate idiosyncratic volatility. Thus, business cycle variables are slightly more important than the corporate variables, and much more important than compositional variables. The significant variables include the variance premium, the market variance, industrial production growth (albeit marginally), and the default spread. However, the sign of the default spread is surprisingly negative.

\footnotetext{
${ }^{10}$ There are a minimum of 9 forecasters and a maximum of 76 forecasters. We also experimented with the methodology in Anderson, Ghysels and Juergens (2009) to downweight the extreme forecasts, which generated highly analogous results. To make the time series monthly, we take the weighted average of the previous and current quarter observations (eg. for January, 2/3 the December observation and 1/3 the March observation,; for February, $1 / 3$ the December observation and 2/3 the March observation). Using the past quarterly observation yields analogous results.
} 


\subsubsection{What drives idiosyncratic variability?}

We now run a horse race between the various determinants. Unfortunately, a regression model using all variables together would be plagued by extreme multi-collinearity and would include many useless and insignificant variables. Our first methodology to pare down the regression model simply uses all the variables that are significant at the $10 \%$ level from the previous subgroup regressions. This regression has 13 regressors. We then eliminate regression variables yielding coefficients that are not significant at the $10 \%$ level and re-run the regression. The result is reported in the fourth section of Table 6 . We find that 7 independent variables explain $80 \%$ of the variation in the aggregate idiosyncratic variance. No compositional variables survive this procedure, but four corporate variables and three business cycle variables survive. The cash flow variables are industry turnover and the growth option variable, the variables stressed by, respectively, Irvine and Pontiff (2008) and Cao, Simin and Zhao (2009); and the research and development spending variables stressed by Chun et al. (2000) and Comin and Philippon (2005). The business cycle variables are the total market variance, the growth in industrial production and the default spread, with the default spread now having the correct sign, indicating higher idiosyncratic variability when credit conditions are bad.

To gauge the relative importance of the various variables in explaining the time variation in idiosyncratic variances, the last column reports a simple covariance decomposition of the fitted value of the regression. Let independent variable $x_{i t}$ have a regression coefficient of $\widehat{b_{i}}$, and denote the fitted value of the regression by $\widehat{y_{t}}$. Then, for each variable, we report the sample analogue of the ratio $\frac{\operatorname{cov}\left(\widehat{b_{i} x_{i}, \widehat{y}_{t}}\right)}{\operatorname{var}\left(\widehat{y}_{t}\right)}$. These ratios add up to one by construction. Clearly, the most important variables are the growth option variable, maba, and market wide volatility. Research 
and development expenditure also explains a non-negligible part of the variation of aggregate idiosyncratic variability.

When applied to the idiosyncratic variances, computed using the FF model, the final "subgroup" model is similar, but it includes four more variables: vwroe, veps, cvmaba and mvp. Qualitatively, the results for the FF model are largely similar, with maba, mkttv and rd accounting for most of the variation in idiosyncratic volatility. We do not report these results to save space.

Research on model reduction techniques by Hendry and Krolzig (2001), among many others, suggests that starting from the most general model yields better specified parsimonious models. We therefore also apply a model reduction technique close in spirit to the PCGets ("generalto-specific") system, proposed and commercialized by Hendry and his associates. The model starts from a regression using all regressors, eliminating insignificant variables, while making sure that the eliminated variables are not jointly significant. We refer to the Online Appendix for more details.

The alternative model selects a less parsimonious model than the model resulting from the subgroup regressions, but the qualitative results are largely the same. The few additional variables retained increase the $\mathrm{R} 2$ to $86 \%$, yet, the key variables of before, the growth option variable and market volatility, now also are the most important variables. Of the additional variables, very few are both statistically and economically significant. The main exception is the variance premium which is highly statistically significant and contributes $10 \%$ to the predicted variance.

Our results shed new light on the debate regarding the determinants of the time-variation 
in U.S. aggregate idiosyncratic volatility. We find that compositional and behavioral variables are relatively unimportant, failing to survive in our first multivariate model, and barely accounting for $10 \%$ of the total in the second (unreported) model. Corporate variables account for $55-60 \%$ of the explained variation, leaving a significant part of the variation to business cycle variables. The addition of these latter variables, not examined before, helps increase the explained variation to over $80 \%$.

The Role of Business Cycle Variables Why are these business cycle variables so important? There are two main possibilities. First, the business cycle variables may reflect cash flow variability not accounted for by our corporate variables. Second, they may reflect discount rate variation not accounted for in our factor model. Let's start with the cash flow channel. When regressing the aggregate idiosyncratic variance time series onto a NBER recession indicator, we obtain a highly significant positive coefficient. It is possible that true cash flow variability is counter-cyclical, but that measurement error in our variables implies that business cycle variables capture this counter-cyclicality better. The evidence seems largely inconsistent with this interpretation, as most of our cash flow variables either show no significant relation with the NBER recession dummy variable, or a significantly negative relation (e.g. all return on equity variables).

In a more direct analysis, we orthogonalize the corporate variables with respect to all of our business cycle variables and repeat the regression of Table 6 , regressing idiosyncratic variability on "pure" cash flow variables. The $R^{2}$ drops from $56 \%$ to $25 \%$, but the coefficients on some of the most important variables, including maba, hardly change. The coefficients on the return on equity variables and veps do become significantly smaller in absolute magnitude. When we 
reverse the exercise, the $R^{2}$ of the business cycle variables is also cut in half, but importantly, the coefficient on the total market variance hardly changes. These results (available upon request) suggest that some of the explanatory power of the business cycle variables may run through cash flow variability and is related to the corporate variables we use, but a significant part is totally independent of it.

One obvious candidate for the independent explanatory power of business cycle variables is the presence of discount rate variation not accounted for in our factor model. To assess the validity of this interpretation, we replace our business cycle variables by a risk premium proxy extracted from these variables. Specifically, we run a regression of market excess returns at time $t+1$ onto the 7 variables at time t. The fitted value of this regression is an estimate of the risk premium on the market, which naturally varies through time. We then repeat our explanatory analysis of aggregate idiosyncratic variance, but we replace the business cycle variables by this risk premium proxy. Consequently, in this regression the business cycle variables only enter to the extent that they can predict market excess returns. Despite using only one business cycle variable, the explanatory power of the regression, pared down using the Hendry approach, only drops from $86 \%$ to $69 \%$. The risk premium variable is highly significant, and it accounts for $26 \%$ of the explained variation. This suggests that more than half of the explanatory power of the business cycle variables is related to these variables capturing discount rate variation not accounted for by standard risk models. The current literature on return predictability suggests that most of the predictable variation is concentrated in recession periods (see e.g. Henkel, Martin and Nardari (2009)), and it is this time-variation in discount rates that standard models of risk may not quite capture, leading to common risk factors contaminating estimates 
of idiosyncratic variance.

Our analysis is related but more comprehensive than the recent work by Zhang (2010), who also runs a horse race between explanatory variables for aggregate U.S. idiosyncratic variability, but with a more limited set of variables. He uses the return on equity and maba, but he uses one variable we do not use: institutional ownership (see our discussion above and note that this variable is highly correlated with our "dto" variable). Zhang (2010) finds the "fundamentals" variables to be the more robust determinants of idiosyncratic variability. He also notes that there is a trend upward in idiosyncratic volatility from 1980 till 2000, and a trend downward after 2000. In his empirical analysis, he allows for different coefficients in the two periods and finds some evidence in favor of coefficient changes. We examine the possibility of shifts in the relationship between idiosyncratic variance and its determinants in more detail in the next sub-section.

\subsubsection{Explaining Regime Switches and Regression Fit}

Specification tests, applied to the residuals of the regression models, reveal that they do not fully fit the time series dynamics of the aggregate idiosyncratic variances. To conserve space, all results referred to in this section are reported in a detailed table in the Online Appendix.

To explore this further, we estimate a regime-switching model for the regression residuals, using the exact same specification as in Section 3. However, because the residuals ought to have mean zero, we identify the two regimes by their variability rather than their mean. The mean level of residuals is not significantly different across regimes, but the regression residuals exhibit significant autocorrelation. There is, of course, still some regime switching behavior left 
in the variance, and the variances in two regimes are significantly different.

Finally, we investigate whether the coefficients in the regression models vary with the regime. We therefore let each coefficient (including the intercept) in the two final models depend on a regime 2 dummy variable, which takes the value of 1 if the smoothed probability of being in regime 2 is higher than 0.5 and 0 otherwise. Across the two regressions, roughly half of the dummy coefficients are significantly different from zero. When significant, the coefficients mostly become larger in magnitude in regime 2 . This is true for the two most important determinants, namely maba and aggregate market volatility. Overall, allowing for this non-linearity improves the $R^{2}$ in both models by about $10 \%$, making it nearly perfect. It is conceivable that this non-linear dependence reflects a "crisis" effect, where in turbulent times all volatility measures increase dramatically. We further reflect on this in the conclusions.

\subsection{International Analysis}

As Table 5 Panel B shows, our international data are much more limited than the U.S. data. First, we do not construct compositional variables. DataStream gradually increased its coverage of international firms over time, which makes the time-series of compositional variables difficult to interpret. Fortunately, the U.S. analysis suggests these variables are far less important than corporate and business cycle variables. Moreover, many of our variables are only available at the annual frequency. With such limited data, the best we can do is run a panel analysis. We create country specific variables for the fundamentals and the business cycle variables, except for the variance premium where we simply use the U.S. values as an indicator of global risk appetite. We consider two different models for the international analysis. 
In a first model, we simply take the same model as we applied to the U.S., using countryspecific explanatory variables, but pooling the coefficients across the G7 countries. The panel model uses country dummies and clusters the standard errors on year, so that correlations between countries are taken into account. The assumption of pooled coefficients is restrictive, but because the sample only starts in 1983 , we have only 26 time series observations. Thus, imposing such restrictions is necessary. Table 7 reports the results from the sub-group regressions; an Online Appendix contains the Hendry model results. For the sub-group analysis, we end up with 7 significant variables, indto and the three maba variables, among the fundamentals; and market volatility, the term spread and the U.S. variance premium, among the business cycle variables. Market wide variability is now the most important determinant accounting for $31 \%$ of the predictable variation. The business cycle variables jointly account for about $55 \%$ of the predictable variation, the corporate variables for about $45 \%$ with maba still being the most important cash flow variable. This decomposition reverses the relative importance of the corporate versus business cycle variables relative to the U.S. results, but it is at the same time rather similar. A surprising result is the importance of the U.S. market variance premium as a determinant of time series movements in international idiosyncratic variances. Note that this decomposition excludes the effect of the country dummies. The country dummies by themselves account for about $14 \%$ of the $69 \% R^{2}$ of the model.

When we consider the Hendry model, the results are largely similar. In the decomposition, it is again "maba", the growth option proxy, consistent with the U.S. results, that is by far the most important corporate variable. Among the business cycle variables, the decomposition again reveals that about $30 \%$ of the total explained variation is accounted for by the total market 
variance, and about $20 \%$ by the variance premium. The split between corporate variables and business cycle variables is now about 50-50.

One interesting question to be addressed, is how much of the strong international commonality in idiosyncratic variances these models can explain. Table 8 provides the answer. We first report the correlation for the original raw data and then for the residuals of the two regression models we just discussed. With few exceptions, the correlations drop rather substantially, often becoming negative. While the correlations do not seem negligible in many cases, they are statistically much closer to zero than the original, raw correlations. Of the 21 correlations, 16 were originally statistically significantly different from zero. Using regression residuals, only 9(6) significant correlations remain when we use the subgroup (Hendry) model ${ }^{11}$.

The second model we consider recognizes the strong correlation between idiosyncratic volatilities across countries, and investigates whether country-specific determinants of idiosyncratic variability are still important once we control for a "U.S. factor" in idiosyncratic variances. The model is as follows:

$$
\sigma_{i, t}^{2}=\beta_{i} \sigma_{U S, t}^{2}+\gamma^{\prime}\left(z_{i, t}-z_{U S, t}\right)+e_{i, t}
$$

That is, we allot each country a beta relative to the U.S., and then see if differences in the usual explanatory variables, $z_{i, t}-z_{U S, t}$, further explain time-variation in the idiosyncratic variance. The results are reported in the Online Appendix. We find that all betas with respect to the

\footnotetext{
${ }^{11}$ It is difficult to dismiss the possibility of a missing common factor. In that scenario, country residuals should still show significant correlations. In the CLMX model these residuals are by construction zero. When we use the FF model, the average correlation among the residuals is $23 \%$, but when we employ the international BHZ model, the average correlation becomes $12 \%$. This indicates that the domestic risk models do omit important systematic variation.
} 
U.S.'s variance are highly statistically significant, and economically account for most of the explained variance. While most of the explanatory variables surviving remain similar to what we found in the first model ${ }^{12}$, their explanatory power has become very limited, compared to the first model. The contribution to the explained variance only remains economically significant for the variance premium. In other words, the joint comovement with the U.S. captures most of the explained variance and the economic importance of market volatility in explaining idiosyncratic volatility seems to be primarily U.S. driven. Of course, such a conclusion may change if we had better international data, but it again confirms the importance of the common component in idiosyncratic variances.

\section{Conclusions}

This article first documents a simple fact: there is no upward trend in idiosyncratic volatility anywhere in the developed world. Instead, we find that idiosyncratic volatility is well described by a stationary regime-switching, mean-reverting process with occasional shifts to a higher-mean, higher-variance regime. While a substantial literature has attempted to explain trending behavior in idiosyncratic volatilities, because of the findings of a trend in CLMX, such explanations should be redirected to explain regime switching behavior.

Such explanations include the increasing propensity of firms to issue public equity at an earlier stage in their life cycle, and more volatile cash flows / fundamentals. We conduct a comprehensive horse race using the variables proposed in the literature regarding index composition

\footnotetext{
${ }^{12}$ This would not be surprising if the betas were all close to one, as then the second model is implied by the first model we estimated.
} 
and cash flow variability, but we added business cycle variables and market wide variability to the mix. We find that the cash flow variables (especially a growth option proxy, market to book value of assets), various business cycle variables and market wide volatility are the most important determinants of the time variation in U.S. aggregate idiosyncratic variability. However, a linear regression model does not eliminate the regime switching characteristics of the idiosyncratic variability, and we find a significant regime dependence of the regression coefficients.

One potential explanation is that in times of crisis, all risk variables increase disproportionately in ways that are hard to capture by simple linear models. It may be that a correlated and therefore undiversifiable tail risk exposure of firms that is present in deep crises such as the recent financial crisis may be driving the common movement in aggregate idiosyncratic volatility across countries. To provide some initial exploration, we define a crisis or bear market to be a market return two standard deviations below the mean for the U.S. sample series over 1980-2008 (to be consistent with our international sample). Aggregate idiosyncratic volatility is $22.2 \%$ in crises, much higher than the sample average of $9.3 \%$, just as aggregate market volatility is also considerably higher in bear markets. Using the U.S.-based definition of a crisis to investigate idiosyncratic variance in other countries, we find that idiosyncratic variance is uniformly higher in these crisis periods than in normal periods, typically by a large margin. On average, the average idiosyncratic variance over the G7 countries is $16.4 \%$ in crises, much higher than the sample average of $7.5 \%$. Note that these U.S. crises also represent local crises, as the mean return is $-12.1 \%$ over the G7 countries. In a nice analogy with findings regarding international return correlations (see Longin and Solnik, 2001; Ang and Bekaert, 2002), idiosyncratic variances are also much more highly correlated across countries during crises. In fact, the difference between 
normal and bear market correlations is much larger for idiosyncratic volatilities than it is for actual returns. For actual returns, the G7 correlation is on average $52 \%$, and the bear market correlation is $60.9 \%$; for idiosyncratic volatilities, the average correlation across G7 countries is $56 \%$, but the bear market correlation is $80.3 \%$. While extreme movements in discount rates may be part of the story here, a full explanation of this phenomenon is beyond the scope of the $\operatorname{article~}^{13}$.

Consequently, the crisis interpretation may also partially explain another new finding in this article: idiosyncratic variability is highly correlated across countries, and this correlation has increased over time. Preliminary work with a linear model for annual data also detected some significant explanatory power for corporate variables, the business cycle and market wide volatility, and the model did succeed in significantly reducing the correlation across countries, suggesting part of the comovement may have a fundamental explanation.

\footnotetext{
${ }^{13}$ We performed some preliminary work with a regime switching model for the US long sample accommodating three regimes. The third regime captures periods of extremely high idiosyncratic volatility, and such periods, apart from a short period during the "Tech bubble", mostly coincide with periods of market stress and low stock returns, such as the October 1987 crisis, the bear market in 1998-2002, and the recent crisis period in 2008.
} 


\section{References}

Aktas, N., E. De Bodt, and J. Cousin, 2007, Assessing the Power and the Size of the Event Study Method through the Decades, working paper.

Anderson, E. W., E. Ghysels, and J. L. Juergens, 2009, The Impact of Risk and Uncertainty on Expected Returns, Journal of Financial Economics, 94, 233-263.

Ang, A. and G. Bekaert, 2002, International asset allocation with regime shifts, Review of Financial Studies, 15(4), 1137-1187.

Ang, A., R. J. Hodrick, Y. Xing and X. Zhang, 2006, The Cross-Section of Volatility and Expected Returns, Journal of Finance, 61, 259-299.

Ang, A., R. J. Hodrick, Y. Xing and X. Zhang, 2009, High Idiosyncratic Volatility and Low Returns: International and Further U.S. Evidence, Journal of Financial Economics, 91, 2-23.

Baele, L., Bekaert, G., and K. Inghelbrecht, 2010, The Determinants of Stock and Bond Return Comovements, Review of Financial Studies, 23, 2374-2428.

Bai, J. and P. Perron, 1998, Estimating and Testing Linear Models with Multiple Structural Changes, Econometrica, 66, 47-78.

Bali, T. G., N. Cakici, and H. Levy, 2008, A Model-Independent Measure of Aggregate Idiosyncratic Risk, Journal of Empirical Finance, 15, 878-896.

Bali, T. G., and A. Hovakimian, 2009, Volatility Spreads and Expected Stock Returns, Management Science, 55, 1797-1812.

Bartram, S., G. Brown and R. Stulz, 2009, Why Do Foreign Firms Have Less Idiosyncratic Risk than U.S. Firms? Working paper.

Bekaert, G., and E. Engstrom, 2009, Asset Return Dynamics under Bad Environment-Good 
Environment Fundamentals, working paper.

Bekaert, G., R. J. Hodrick and X. Zhang, 2009, International Stock Return Comovements, Journal of Finance, 64, 2591-2626.

Bennett, J. A., R. W. Sias, and L. T. Starks, 2003, Greener Pastures and the Impact of Dynamic Institutional Preferences, Review of Financial Studies, 16, 1203-1238.

Bollerslev, T., Tauchen, G. E., and Zhou, H., 2009, Expected Stock Returns and Variance Risk Premia, Review of Financial Studies, 22, 4463-4492.

Brandt, M. W., A. Brav, J. Graham, and A. Kumar, 2010, The Idiosyncratic Volatility Puzzle: Time Trend or Speculative Episodes? Review of Financial Studies, 23, 863-899.

Brown, G., and N. Kapadia, 2007, Firm-Specific Risk and Equity Market Development, Journal of Financial Economics, 84, 358-388.

Bunzel, H. and T. J. Vogelsang, 2005, Powerful Trend Function Tests That Are Robust to Strong Serial Correlation, with an Application to the Prebisch-Singer Hypothesis, Journal of Business and Economic Statistics, 381-394.

Campbell, J. Y., M. Lettau, B. G. Malkiel and Y. Xu, 2001, Have individual stocks become more volatile? An empirical exploration of idiosyncratic risk. Journal of Finance, 56, 1-43.

Cao, C., T. Simin and J. Zhao, 2007, Can Growth Options Explain the Trend in Idiosyncratic Risk? Review of Financial Studies, 2599-2633.

Carr, P., and L. Wu, 2009, Variance Risk Premiums, Review of Financial Studies 22, 13111341.

Chun, H., J. Kim, R. Morck and B. Yeung, 2007, Creative Destruction and Firm-Specific Performance Heterogeneity, Journal of Financial Economics, 109-135. 
Comin, D. and S. Mulani, 2006, Diverging Trends in Macro and Micro Volatility: Facts, Review of Economics and Statistics, 374-383.

Comin, D. and T. Philippon, 2005, The Rise in Firm-Level Volatility: Causes and Consequences, NBER Macroeconomics Annual 2005, 20, NBER, MA, in (eds.) M. Gertler and K. Rogoff.

Dickey, D. and W. Fuller, 1979, Distribution of the estimators for autoregressive time series with a unit root. Journal of the American Statistical Association 74, 427-431.

Drechsler, I. 2009, Uncertainty, Time-Varying Fear, and Asset Prices, working paper

Drechsler, I., and A. Yaron, What's Vol Got to Do With It, forthcoming, Review of Financial Studies.

Fama, E. F. and K. R. French, 1996, Multifactor explanations of asset pricing anomalies, Journal of Finance 51, 55-84.

Ferreira, M. and P. Gama, 2005, Have world, country and industry risks changed over time? An investigation of the developed stock market volatility, Journal of Financial and Quantitative Analysis, 40, 195-222.

Ferreira, M. and P. Laux, 2007, Corporate governance, idiosyncratic risk, and information flow, Journal of Finance, 62, 951-990.

Fink, J., K. Fink, G. Grullon, and J. Weston, 2010, What Drove the Increase in Idiosyncratic Volatility during the Internet Boom?, Journal of Financial and Quantitative Analysis 45, 12531278.

Foucault, T., D. Sraer, and D. Thesmar, 2008, "Individual Investors and Volatility", Working paper. 
Gaspar, J. and M. Massa, 2006, Idiosyncratic Volatility and Product Market Competition, Journal of Business, 3125-3152.

Gilchrist, S., V. Yankov and E. Zakrajsek, 2009, Credit Market Shocks and Economic Fluctuations: Evidence from Corporate Bond and Stock Markets, working paper.

Guo, H., and R. Savickas, 2008, Average Idiosyncratic Volatility in G7 Countries, Review of Financial Studies, 21, 1259-1296.

Hamilton, J. D., 1994, Time-Series Analysis, Prentice Hall.

Harvey, C., 1988, The Real Term Structure and Consumption Growth, Journal of Financial Economics 22, 305-334.

Henkel, S., J. C. Martin and F. Nardari, 2009, Time-varying Short Horizon Return Predictability, forthcoming, Journal of Financial Economics.

Hendry, D. F., and H.-M. Krolzig, 2001, Automatic Econometric Model Selection, London. Irvine, P. J., and J. Pontiff, 2008, Idiosyncratic Return Volatility, Cash Flows, and Product Market Competition, Review of Financial Studies, 1149-1177.

Jin, L. and S. C. Myers, 2006, "R2 Around the World: New Theory and New Tests," Journal of Financial Economics, 71, 257-292.

Kothari, S. P. and Warner, J. B., 2004, The Econometrics of Event Studies, unpublished working paper.

Longin, F. and B. Solnik, 2001, Extreme Correlation of International Equity Markets, Journal of Finance, 56, 649-676.

Morck, R., B. Yeung and W. Yu, 2000, The Information Content of Stock Markets: Why Do Emerging Markets Have Synchronous Stock Price Movements? Journal of Financial Economics 
$59,215-260$.

Mueller, P., 2009, Credit Spreads and Real Activity, working paper.

Pastor, L. and P. Veronesi, 2003, Stock Valuation and Learning about Profitability, Journal of Finance, 58, 1749-1789.

Phillips, P. and P. Perron, 1988. Testing for a Unit Root in Time Series Regression, Biometrika $75,335-346$.

Schwert, G. W., 1989, Why does Stock Market Volatility Change Over Time, Journal of Finance, 44 (5), 1115-1153.

Schwert, G. W., 1990, Stock Volatility and the Crash of '87, Review of Financial Studies, 3 (1990) 77-102.

Timmermann, A., 2000, Moments of Markov Switching Models, Journal of Econometrics, $96,75-111$.

Vogelsang, T., 1998, Trend function hypothesis testing in the presence of serial correlation, Econometrica 66, 123-148.

Wei, S. X., and C. Zhang, 2006, Why Did Individual Stocks Become More Volatile?, Journal of Business, 79, 259-292.

White, H., 1980, A Heteroskedasticity-Consistent Covariance Matrix Estimator and a Direct Test for Heteroskedasticity, Econometrica 48, 817-838.

Xu, Y., and B. G. Malkiel, 2003, Investigating the Behavior of Idiosyncratic Volatility, Journal of Business, 76, 613-644.

Zhang, C., 2010, A Re-examination of the Causes of Time-varying Stock Return Volatilities, Journal of Financial and Quantitative Analysis 45, 663-684. 
Table 1. Idiosyncratic variance summary statistics

Panel A provides summary statistics for the U.S. sample of January 1964 to December 2008. Panel B reports summary statistics for the developed countries sample of January 1980 to December 2008. Panel C presents correlations between G7 idiosyncratic variances. We use bold font if the correlation is significantly different from zero at the $5 \%$ level. The U.S. return data are obtained from CRSP, and the return data for other countries are obtained from DataStream. All the returns are denominated in U.S. dollars. The variables $\sigma_{C L M X}^{2}$ and $\sigma_{F F}^{2}$ are the aggregate firm level idiosyncratic variances, as defined in equations (2) and (4), respectively. All variance timeseries statistics are annualized.

Panel A. U.S. sample, 1964 - 2008

\begin{tabular}{c|cc|cc}
\hline & \multicolumn{2}{|c|}{$\sigma_{\text {CLMX }}^{2}$} & \multicolumn{2}{c}{$\sigma_{F F}^{2}$} \\
$\mathrm{~N}$ & Mean & Std & Mean & Std \\
\hline 540 & 0.0800 & 0.0592 & 0.0697 & 0.0484 \\
\hline
\end{tabular}

Panel B. Developed countries sample, 1980 - 2008

\begin{tabular}{l|c|cc|cc}
\hline & & \multicolumn{2}{|c|}{$\sigma_{\text {CLMX }}^{2}$} & \multicolumn{2}{c}{$\sigma_{F F}^{2}$} \\
\hline & $\mathrm{N}$ & Mean & Std & Mean & Std \\
\hline CANADA & 342 & 0.0880 & 0.0476 & 0.0844 & 0.0433 \\
FRANCE & 342 & 0.0692 & 0.0377 & 0.0696 & 0.0386 \\
GERMANY & 342 & 0.0537 & 0.0655 & 0.0492 & 0.0426 \\
ITALY & 342 & 0.0758 & 0.0536 & 0.0727 & 0.0485 \\
JAPAN & 342 & 0.0912 & 0.0487 & 0.0815 & 0.0426 \\
U.K. & 342 & 0.0529 & 0.0429 & 0.0550 & 0.0459 \\
U.S. & 342 & 0.0931 & 0.0661 & 0.0814 & 0.0544 \\
AUSTRALIA & 342 & 0.0745 & 0.0482 & 0.0712 & 0.0455 \\
AUSTRIA & 342 & 0.0413 & 0.0503 & 0.0433 & 0.0422 \\
BELGIUM & 342 & 0.0487 & 0.0584 & 0.0459 & 0.0367 \\
DENMARK & 342 & 0.0473 & 0.0297 & 0.0523 & 0.0365 \\
FINLAND & 288 & 0.0547 & 0.0527 & 0.0711 & 0.0529 \\
GREECE & 251 & 0.0901 & 0.0701 & 0.0798 & 0.0480 \\
HK & 342 & 0.0792 & 0.0564 & 0.0710 & 0.0454 \\
IRELAND & 342 & 0.0474 & 0.0598 & 0.0683 & 0.0683 \\
NETHERLANDS & 342 & 0.0292 & 0.0303 & 0.0369 & 0.0322 \\
NEW ZEALAND & 275 & 0.0404 & 0.0311 & 0.0518 & 0.0252 \\
NORWAY & 342 & 0.0800 & 0.0526 & 0.0859 & 0.0537 \\
PORTUGAL & 251 & 0.0677 & 0.0958 & 0.0597 & 0.0385 \\
SINGAPORE & 342 & 0.0656 & 0.0556 & 0.0591 & 0.0388 \\
SPAIN & 275 & 0.0435 & 0.0406 & 0.0457 & 0.0361 \\
SWEDEN & 342 & 0.0568 & 0.0425 & 0.0664 & 0.0403 \\
SWITZERLAND & 342 & 0.0312 & 0.0292 & 0.0326 & 0.0262 \\
\hline
\end{tabular}


Panel C. Correlations between the idiosyncratic variances of the G7 countries, 1980 - 2008

\begin{tabular}{|c|c|c|c|c|c|c|}
\hline & \multicolumn{6}{|l|}{$\sigma_{C L M X}^{2}$} \\
\hline & Canada & France & Germany & Italy & Japan & U.K. \\
\hline France & $56 \%$ & & & & & \\
\hline Germany & $62 \%$ & $57 \%$ & & & & \\
\hline Italy & $31 \%$ & $51 \%$ & $20 \%$ & & & \\
\hline Japan & $56 \%$ & $54 \%$ & $57 \%$ & $23 \%$ & & \\
\hline U.K. & $74 \%$ & $68 \%$ & $81 \%$ & $31 \%$ & $72 \%$ & \\
\hline \multirow[t]{3}{*}{ U.S. } & $75 \%$ & $65 \%$ & $68 \%$ & $20 \%$ & $70 \%$ & $80 \%$ \\
\hline & $\sigma_{F F}^{2}$ & & & & & \\
\hline & Canada & France & Germany & Italy & Japan & U.K. \\
\hline France & $63 \%$ & & & & & \\
\hline Germany & $77 \%$ & $67 \%$ & & & & \\
\hline Italy & $32 \%$ & $53 \%$ & $19 \%$ & & & \\
\hline Japan & $65 \%$ & $62 \%$ & $71 \%$ & $31 \%$ & & \\
\hline U.K. & $68 \%$ & $62 \%$ & $74 \%$ & $33 \%$ & $70 \%$ & \\
\hline U.S. & $76 \%$ & $71 \%$ & $81 \%$ & $27 \%$ & $72 \%$ & $71 \%$ \\
\hline
\end{tabular}


Table 2. Trend tests

Panel A and Panel B reports trend test results for the U.S. idiosyncratic variance time-series, and Panel C reports trend test results for the idiosyncratic variance time-series of all developed countries. All panels use Vogelsang's (1998) t-PS1 test and Bunzel and Vogelsang's (2008) tdan test. The $5 \%$ critical value (two sided) for t-dan is 2.052, and for t-ps1 is 2.152. We report both pre-whitened results using AR (1) and non-pre-whitened results for the t-dan test in Panel A and $\mathrm{B}$, and for Panel $\mathrm{C}$, we only use the pre-whitened results. Variables $\sigma_{C L M X}^{2}, \sigma_{F F}^{2}$ and $\sigma_{B C L}^{2}$ are the aggregate firm level idiosyncratic variances, as defined in equations (2), (4) and (6), respectively. All variance time-series statistics are annualized. All coefficients are multiplied by 100.

Panel A. Idiosyncratic variances over 1964-1997, daily data

\begin{tabular}{l|llll|lc}
\hline & \multicolumn{2}{|c}{ Pre-whitened } & \multicolumn{2}{c|}{ Not pre-whitened } & \multicolumn{2}{c}{} \\
& b-dan & t-dan & b-dan & t-dan & b-ps1 & t-ps1 \\
\hline$\sigma_{C L M X}^{2}$ & 0.011 & 4.84 & 0.011 & 4.97 & 0.011 & 3.89 \\
$\sigma_{F F}^{2}$ & 0.009 & 4.35 & 0.009 & 4.72 & 0.009 & 3.36 \\
$\sigma_{B C L}^{2}$ & 0.007 & 3.27 & 0.007 & 3.37 & 0.007 & 2.51 \\
\hline
\end{tabular}

Panel B. Idiosyncratic variances over 1964-2008, daily data

\begin{tabular}{l|cccc|cc}
\hline & \multicolumn{2}{|c}{ Pre-whitened } & \multicolumn{2}{c|}{ Not pre-whitened } & \multicolumn{2}{c}{} \\
& b-dan & t-dan & b-dan & t-dan & b-ps1 & t-ps1 \\
\hline$\sigma_{C L M X}^{2}$ & 0.015 & 0.95 & 0.015 & 1.04 & 0.016 & 1.35 \\
$\sigma_{F F}^{2}$ & 0.013 & 0.76 & 0.013 & 0.87 & 0.014 & 1.15 \\
$\sigma_{B C L}^{2}$ & 0.012 & 0.93 & 0.012 & 1.00 & 0.014 & 1.18 \\
\hline
\end{tabular}


Panel C. Idiosyncratic variances over 1980-2008, daily data

\begin{tabular}{l|cccc|cccc}
\hline & \multicolumn{4}{|c|}{$\sigma_{\text {CLMX }}^{2}$} & \multicolumn{4}{c}{$\sigma_{B C L}^{2}$} \\
& b-dan & t-dan & b-ps1 & t-ps1 & b-dan & t-dan & b-ps1 & t-ps1 \\
\hline CANADA & 0.059 & 0.35 & 0.097 & 0.48 & 0.014 & 0.31 & 0.014 & 0.46 \\
FRANCE & -0.090 & -0.28 & -0.004 & -0.01 & 0.001 & 0.06 & 0.005 & 0.23 \\
GERMANY & 0.290 & 0.48 & 0.346 & 0.73 & 0.020 & 0.66 & 0.021 & 0.84 \\
ITALY & -0.414 & -2.62 & -0.375 & -1.86 & -0.014 & -1.21 & -0.014 & -0.95 \\
JAPAN & 0.016 & 0.07 & 0.050 & 0.23 & 0.006 & 0.29 & 0.009 & 0.40 \\
U.K. & 0.070 & 0.06 & 0.053 & 0.08 & 0.012 & 0.27 & 0.012 & 0.38 \\
U.S. & 0.053 & 0.03 & 0.141 & 0.15 & 0.013 & 0.32 & 0.020 & 0.51 \\
AUSTRALIA & -0.055 & -0.27 & -0.125 & -0.81 & -0.001 & -0.03 & -0.010 & -0.57 \\
AUSTRIA & 0.496 & 0.93 & 0.543 & 0.82 & 0.017 & 0.45 & 0.012 & 0.79 \\
BELGIUM & -0.052 & -0.06 & -0.058 & -0.13 & 0.006 & 0.21 & -0.001 & -0.04 \\
DENMARK & 0.065 & 0.37 & 0.126 & 0.50 & 0.011 & 0.46 & 0.011 & 0.52 \\
FINLAND & -0.514 & -0.21 & -0.584 & -0.41 & -0.023 & -1.01 & -0.024 & -0.97 \\
GREECE & -0.323 & -1.57 & -0.377 & -1.77 & -0.017 & -0.83 & -0.021 & -1.02 \\
HK & 0.030 & 0.14 & 0.001 & 0.00 & 0.000 & -0.02 & -0.003 & -0.14 \\
IRELAND & 0.077 & 0.08 & -0.008 & -0.02 & 0.017 & 0.14 & 0.004 & 0.11 \\
NETHERLANDS & 0.198 & 0.31 & 0.253 & 0.45 & 0.012 & 0.52 & 0.013 & 0.56 \\
NEW ZEALAND & -0.019 & -0.04 & -0.089 & -0.20 & -0.010 & -1.15 & -0.014 & -1.33 \\
NORWAY & 0.017 & 0.06 & 0.060 & 0.18 & 0.003 & 0.21 & 0.002 & 0.11 \\
PORTUGAL & -0.651 & -4.33 & -0.773 & -4.93 & -0.015 & -1.94 & -0.022 & -2.76 \\
SINGAPORE & 0.049 & 0.42 & 0.002 & 0.01 & 0.008 & 0.79 & 0.008 & 0.58 \\
SPAIN & -0.298 & -1.38 & -0.350 & -1.61 & -0.011 & -0.75 & -0.010 & -0.60 \\
SWEDEN & -0.013 & 0.03 & 0.028 & 0.07 & 0.008 & 0.44 & 0.013 & 0.65 \\
SWITZERLAND & 0.120 & 0.41 & 0.159 & 0.51 & 0.008 & 1.21 & 0.008 & 1.15 \\
\hline
\end{tabular}


Table 3. Regime switching model estimation results.

This table reports the regime switching model results for the idiosyncratic variance time-series computed using daily data, where the model is described as follows:

$y_{t}=\left(1-b_{i}\right) \mu_{i}+b_{i} y_{t-1}+\sigma_{i} e_{t}, i=1,2$.

Transition probability matrix $\Phi=\left[\begin{array}{cc}p 11 & 1-p 11 \\ 1-p 22 & p 22\end{array}\right]$.

The transition probability parameters, p11 and p22 are constrained to be in $(0,1)$ during estimation. We also re-parameterize to ensure $0<\mu_{1}<\mu_{2}$. The left half panel reports results for the U.S. The sample period is 1964-2008. The variables $\sigma_{C L M X}^{2}$ and $\sigma_{F F}^{2}$ are the aggregate firm level idiosyncratic variances, as defined in equations (2) and (4), respectively. The right half panel reports results for the aggregate idiosyncratic variance time-series of the G7 countries. The sample period becomes 1980-2008. All variance time-series statistics are annualized.

\begin{tabular}{c|cccc|ccccccc}
\hline & \multicolumn{9}{|c|}{ long sample: 1964-2008 } & \multicolumn{7}{c}{ short sample: 1980-2008 } \\
\hline & \multicolumn{4}{|c|}{ U.S. } & CA & FR & GE & IT & JP & U.K. & U.S. \\
\hline & \multicolumn{2}{|c|}{$\sigma_{\text {CLMX }}^{2}$} & \multicolumn{2}{c|}{$\sigma_{F F}^{2}$} & $\sigma_{C L M X}^{2}$ & $\sigma_{C L M X}^{2}$ & $\sigma_{C L M X}^{2}$ & $\sigma_{C L M X}^{2}$ & $\sigma_{C L M X}^{2}$ & $\sigma_{C L M X}^{2}$ & $\sigma_{C L M X}^{2}$ \\
\hline & coef. & std. & coef. & std. & coef. & coef. & coef. & coef. & coef. & coef. & coef. \\
$\mu_{1}$ & 0.062 & 0.003 & 0.055 & 0.003 & 0.071 & 0.051 & 0.033 & 0.049 & 0.072 & 0.036 & 0.070 \\
$\mu_{2}$ & 0.181 & 0.023 & 0.155 & 0.020 & 0.160 & 0.125 & 0.121 & 0.139 & 0.156 & 0.122 & 0.198 \\
$b_{1}$ & 0.823 & 0.028 & 0.813 & 0.027 & 0.604 & 0.628 & 0.761 & 0.681 & 0.639 & 0.735 & 0.686 \\
$b_{2}$ & 0.585 & 0.090 & 0.677 & 0.080 & 0.226 & 0.273 & 0.316 & 0.431 & 0.564 & 0.584 & 0.512 \\
$\sigma_{1}$ & 0.011 & 0.001 & 0.010 & 0.001 & 0.013 & 0.012 & 0.008 & 0.016 & 0.018 & 0.009 & 0.013 \\
$\sigma_{2}$ & 0.082 & 0.007 & 0.057 & 0.005 & 0.073 & 0.048 & 0.113 & 0.061 & 0.055 & 0.058 & 0.086 \\
$p_{11}$ & 0.981 & 0.008 & 0.987 & 0.007 & 0.934 & 0.904 & 0.933 & 0.927 & 0.952 & 0.940 & 0.984 \\
$p_{22}$ & 0.900 & 0.061 & 0.935 & 0.044 & 0.672 & 0.593 & 0.750 & 0.804 & 0.830 & 0.716 & 0.934 \\
\hline
\end{tabular}


Table 4. The common component in idiosyncratic variances across countries

For each panel, the table reports the correlations of G7 countries' idiosyncratic variance with the U.S. idiosyncratic variance. The different panels use different models to compute idiosyncratic variances. We also report the average correlations in the two regimes identified for the U.S., using smoothed regime probabilities in regime 2.

Panel A. Daily CLMX model

\begin{tabular}{l|ccc|cc}
\hline$\sigma_{C L M X}^{2}$ & \multicolumn{3}{|c|}{ Correlation with U.S. } & \multicolumn{2}{c}{ Correlation with U.S. } \\
\hline & $1980-2008$ & $1980-1994$ & $1995-2008$ & Regime 1 & Regime 2 \\
\hline Canada & $80 \%$ & $63 \%$ & $86 \%$ & $53 \%$ & $82 \%$ \\
France & $66 \%$ & $45 \%$ & $74 \%$ & $51 \%$ & $68 \%$ \\
Germany & $77 \%$ & $49 \%$ & $79 \%$ & $37 \%$ & $57 \%$ \\
Italy & $20 \%$ & $14 \%$ & $47 \%$ & $25 \%$ & $60 \%$ \\
Japan & $66 \%$ & $23 \%$ & $76 \%$ & $28 \%$ & $79 \%$ \\
U.K. & $81 \%$ & $73 \%$ & $81 \%$ & $57 \%$ & $70 \%$ \\
U.S. & $100 \%$ & $100 \%$ & $100 \%$ & $100 \%$ & $100 \%$ \\
\hline
\end{tabular}

Panel B. Daily FF model

\begin{tabular}{l|ccc|cc}
\hline$\sigma_{F F}^{2}$ & \multicolumn{3}{|c|}{ Correlation with U.S. } & \multicolumn{2}{c}{ Correlation with U.S. } \\
\hline & $1980-2008$ & $1980-1994$ & $1995-2008$ & Regime & Regime 2 \\
\hline Canada & $82 \%$ & $64 \%$ & $84 \%$ & $56 \%$ & $68 \%$ \\
France & $73 \%$ & $34 \%$ & $83 \%$ & $41 \%$ & $76 \%$ \\
Germany & $82 \%$ & $40 \%$ & $82 \%$ & $27 \%$ & $73 \%$ \\
Italy & $34 \%$ & $26 \%$ & $57 \%$ & $28 \%$ & $58 \%$ \\
Japan & $69 \%$ & $18 \%$ & $77 \%$ & $24 \%$ & $77 \%$ \\
U.K. & $84 \%$ & $65 \%$ & $86 \%$ & $17 \%$ & $73 \%$ \\
U.S. & $100 \%$ & $100 \%$ & $100 \%$ & $100 \%$ & $100 \%$ \\
\hline
\end{tabular}


Table 5. Explanatory variables

Panel A. For the U.S. analysis

\begin{tabular}{|c|c|}
\hline variable & description \\
\hline \multicolumn{2}{|c|}{ I. Index composition/behavioral variables } \\
\hline pyoung & $\begin{array}{l}\text { the \% of market cap of firms less than } 10 \text { years old since } \\
\text { foundation }\end{array}$ \\
\hline psmall & $\begin{array}{l}\text { the } \% \text { of market cap of firms smaller than } 25 \% \text { of all } \\
\text { firms listed }\end{array}$ \\
\hline plow & $\begin{array}{l}\text { the \% of market cap of firms with share price lower than } \\
\$ 5\end{array}$ \\
\hline lowto & $\begin{array}{l}\text { the average volume turnover for firms with share price } \\
\text { lower than } \$ 5\end{array}$ \\
\hline dto & $\begin{array}{l}\text { aggregate dollar volume over aggregate market } \\
\text { capitalization }\end{array}$ \\
\hline \multicolumn{2}{|c|}{ II. Corporate variables } \\
\hline $\begin{array}{l}\text { vwroe } \\
\text { vwvroe }\end{array}$ & $\begin{array}{l}\text { the value weighted average of firm level return on equity } \\
\text { the value weighted average of 12-quarter time-series } \\
\text { variance of firm level return on equity }\end{array}$ \\
\hline cvroe & the cross-sectional variance of firm level return on equity \\
\hline veps & $\begin{array}{l}\text { the cross-sectional variance of shocks to earnings per } \\
\text { share }\end{array}$ \\
\hline indto & the average industry turnover \\
\hline maba & $\begin{array}{l}\text { the value weighted average of firm level market assets } \\
\text { over book assets }\end{array}$ \\
\hline vmaba & $\begin{array}{l}\text { the value weighted average of } 12 \text {-quarter time-series } \\
\text { variance of firm level market assets over book assets }\end{array}$ \\
\hline cvmaba & $\begin{array}{l}\text { the cross-sectional variance of firm level market assets } \\
\text { over book assets }\end{array}$ \\
\hline rd & $\begin{array}{l}\text { the value weighted average of firm level R\&D } \\
\text { expenditure scaled by sales }\end{array}$ \\
\hline cvrd & $\begin{array}{l}\text { the cross-sectional variance of firm level R\&D } \\
\text { expenditure scaled by sales }\end{array}$ \\
\hline \multicolumn{2}{|c|}{ III. Business cycle variables } \\
\hline dip & the first order difference in industrial production \\
\hline confi & the conference board’s index of consumer confidence \\
\hline def & the yield spread between BAA and AAA corporate bonds \\
\hline term & $\begin{array}{l}\text { the yield spread between } 10 \text { year and } 1 \text { year government } \\
\text { bond }\end{array}$ \\
\hline mvp & the market variance premium \\
\hline mkttv & the market index realized variance \\
\hline disp & $\begin{array}{l}\text { the dispersion of survey forecasts of aggregate corporate } \\
\text { profits growth }\end{array}$ \\
\hline
\end{tabular}


Panel B. For the international analysis

\begin{tabular}{|c|c|}
\hline variable & description \\
\hline \multicolumn{2}{|c|}{ I. Corporate variables } \\
\hline vwroe & the value weighted average of firm level return on equity \\
\hline vwvroe & $\begin{array}{l}\text { the value weighted average of } 12 \text {-quarter time-series } \\
\text { variance of firm level return on equity }\end{array}$ \\
\hline cvroe & the cross-sectional variance of firm level return on equity \\
\hline veps & $\begin{array}{l}\text { the cross-sectional variance of shocks to earnings per } \\
\text { share }\end{array}$ \\
\hline indto & the average industry turnover \\
\hline maba & $\begin{array}{l}\text { the value weighted average of firm level market assets } \\
\text { over book assets }\end{array}$ \\
\hline vmaba & $\begin{array}{l}\text { the value weighted average of } 12 \text {-quarter time-series } \\
\text { variance of firm level market assets over book assets }\end{array}$ \\
\hline cvmaba & $\begin{array}{l}\text { the cross-sectional variance of firm level market assets } \\
\text { over book assets }\end{array}$ \\
\hline \multicolumn{2}{|c|}{ II. Business cycle variables } \\
\hline mkttv & the market index realized variance \\
\hline usmvp & the U.S. market value premium \\
\hline dgdp & the first order difference in each country's annual GDP \\
\hline def & $\begin{array}{l}\text { the yield spread between each country's corporate debt } \\
\text { and government bonds }\end{array}$ \\
\hline term & $\begin{array}{l}\text { the yield spread between each country’s long term and } \\
\text { short term government bonds }\end{array}$ \\
\hline
\end{tabular}


Table 6. What drives U.S. idiosyncratic volatility?

OLS regressions of aggregate idiosyncratic variances in the U.S. over 1964-2008, computed using the CLMX model, on various determinants, labeled on the left. We show 4 regressions, one for each group of variables, and a final one based on a paring down technique picking significant variables from the previous regressions, discussed in the text. All p-values are based on a standard error, using 12 Newey-West lags. The last column reports the covariance decomposition described in the text.

\begin{tabular}{|c|c|c|c|c|c|c|c|c|c|}
\hline & \multicolumn{2}{|c|}{$\begin{array}{l}\text { I. Behavioral and } \\
\text { compositional }\end{array}$} & \multicolumn{2}{|c|}{$\begin{array}{l}\text { II. Corporate } \\
\text { cash flow }\end{array}$} & \multicolumn{2}{|c|}{$\begin{array}{l}\text { III. Business } \\
\text { cycle variables }\end{array}$} & \multicolumn{3}{|c|}{$\begin{array}{l}\text { IV. Significant variables from } \\
\text { I-III }\end{array}$} \\
\hline & coef. & p-value & coef. & $\mathrm{p}$-value & coef. & $\mathrm{p}$-value & coef. & $\mathrm{p}$-value & $\begin{array}{l}\text { Cov } \\
\text { decomp }\end{array}$ \\
\hline pyoung & 0.783 & 0.154 & & & & & & & \\
\hline psmall & -12.380 & 0.084 & & & & & & & \\
\hline plow & -3.903 & 0.072 & & & & & & & \\
\hline lowto & -0.007 & 0.750 & & & & & & & \\
\hline dto & 0.043 & 0.216 & & & & & & & \\
\hline vwroe & & & 1.342 & 0.020 & & & & & \\
\hline vwvroe & & & -5.053 & 0.380 & & & & & \\
\hline cvroe & & & -0.564 & 0.311 & & & & & \\
\hline veps & & & 0.014 & 0.028 & & & & & \\
\hline indto & & & 0.006 & 0.010 & & & 0.006 & 0.003 & $2 \%$ \\
\hline maba & & & 0.083 & 0.013 & & & 0.091 & 0.000 & $42 \%$ \\
\hline vmaba & & & -0.006 & 0.559 & & & & & \\
\hline cvmaba & & & 0.001 & 0.071 & & & & & \\
\hline rd & & & 0.251 & 0.029 & & & 0.140 & 0.034 & $26 \%$ \\
\hline cvrd & & & -0.008 & 0.002 & & & -0.006 & 0.000 & $-10 \%$ \\
\hline mvp & & & & & 1.405 & 0.001 & & & \\
\hline mkttv & & & & & 0.697 & 0.000 & 0.726 & 0.000 & $40 \%$ \\
\hline dip & & & & & -0.664 & 0.053 & -0.842 & 0.008 & $1 \%$ \\
\hline def & & & & & -0.025 & 0.021 & 0.019 & 0.001 & $-2 \%$ \\
\hline term & & & & & -0.004 & 0.176 & & & \\
\hline confi & & & & & 0.0002 & 0.446 & & & \\
\hline disp & & & & & -0.604 & 0.473 & & & \\
\hline Adj. R2 & $35 \%$ & & $56 \%$ & & $57 \%$ & & $80 \%$ & & \\
\hline
\end{tabular}


Table 7. Idiosyncratic volatility across G7 countries?

OLS regressions of aggregate idiosyncratic variances in the G7 countries over 1983-2008, computed using the CLMX model, on various determinants, labeled on the left. The annual data time series for idiosyncratic variance are average over monthly observations in the year. More details about data are in Appendix B. We show 3 regressions, one for each group of variables, and a final one based on a paring down technique picking significant variables from the previous regressions, discussed in the text. All regressions include country dummies. All p-values are based on a standard error using 12 Newey-West lags and they are adjusted by clustering on years. All regressions include country dummies. The last column reports the covariance decomposition described in the text.

\begin{tabular}{|c|c|c|c|c|c|c|c|}
\hline & \multicolumn{2}{|c|}{$\begin{array}{l}\text { I. Corporate } \\
\text { cash flow }\end{array}$} & \multicolumn{2}{|c|}{$\begin{array}{c}\text { II. Business } \\
\text { cycle variables }\end{array}$} & \multicolumn{3}{|c|}{ III. Significant variables } \\
\hline & coef. & p-value & coef. & p-value & coef. & p-value & $\begin{array}{c}\text { Cov } \\
\text { decomp }\end{array}$ \\
\hline vwroe & -0.129 & 0.299 & & & & & \\
\hline vwvroe & 0.129 & 0.918 & & & & & \\
\hline cvroe & 0.232 & 0.234 & & & & & \\
\hline veps & 0.042 & 0.153 & & & & & \\
\hline indto & 0.133 & 0.007 & & & 0.062 & 0.033 & $0.3 \%$ \\
\hline maba & 0.024 & 0.000 & & & 0.022 & 0.000 & $25.2 \%$ \\
\hline vmaba & 0.004 & 0.000 & & & 0.002 & 0.036 & $7.2 \%$ \\
\hline cvmaba & 0.003 & 0.088 & & & 0.003 & 0.001 & $11.3 \%$ \\
\hline mkttv & & & 0.455 & 0.000 & 0.459 & 0.000 & $31.1 \%$ \\
\hline dgdp & & & -0.035 & 0.225 & & & \\
\hline def & & & -0.001 & 0.702 & & & \\
\hline term & & & -0.004 & 0.094 & -0.002 & 0.061 & $0.4 \%$ \\
\hline usmvp & & & 1.180 & 0.001 & 0.916 & 0.002 & $24.4 \%$ \\
\hline Adj. R2 & $41 \%$ & & $56 \%$ & & $69 \%$ & & \\
\hline Adj. R2 (w/o & & & & & & & \\
\hline $\begin{array}{l}\text { country } \\
\text { dummies) }\end{array}$ & $27 \%$ & & $41 \%$ & & $55 \%$ & & \\
\hline
\end{tabular}


Table 8. Correlations for the annual idiosyncratic volatility data

This table reports correlations for annual data of aggregate idiosyncratic variance time-series. Panel A reports correlation coefficients for the original annual idiosyncratic variance data. Panels $\mathrm{B}$ and $\mathrm{C}$ report correlation coefficients for the residuals from the final regression in the subgroup model and Hendry model, respectively. The bold font indicates that the correlation is significant at the $5 \%$ level using a Pearson test.

Panel A. Correlation for original annual idiosyncratic variances

\begin{tabular}{ccccccc}
\hline & CANADA & FRANCE & GERMANY & ITALY & JAPAN & UK \\
\hline FRANCE & $\mathbf{7 7 \%}$ & & & & & \\
GERMANY & $\mathbf{8 5 \%}$ & $\mathbf{6 7 \%}$ & & & & \\
ITALY & $14 \%$ & $\mathbf{5 5 \%}$ & $2 \%$ & & & \\
JAPAN & $\mathbf{7 5 \%}$ & $\mathbf{7 8 \%}$ & $\mathbf{7 4 \%}$ & $29 \%$ & & \\
UK & $\mathbf{8 7 \%}$ & $\mathbf{7 4 \%}$ & $\mathbf{9 0 \%}$ & $19 \%$ & $\mathbf{8 6 \%}$ & \\
US & $\mathbf{9 2 \%}$ & $\mathbf{8 1 \%}$ & $\mathbf{8 2 \%}$ & $21 \%$ & $\mathbf{8 4 \%}$ & $\mathbf{8 9 \%}$ \\
\hline
\end{tabular}

Panel B. Correlation for regression residuals from the subgroup model

\begin{tabular}{ccccccc}
\hline & CANADA & FRANCE & GERMANY & ITALY & JAPAN & UK \\
\hline FRANCE & $\mathbf{6 5 \%}$ & & & & & \\
GERMANY & $35 \%$ & $-26 \%$ & & & & \\
ITALY & $20 \%$ & $\mathbf{7 1 \%}$ & $\mathbf{- 5 2 \%}$ & & & \\
JAPAN & $\mathbf{4 9 \%}$ & $\mathbf{4 2 \%}$ & $\mathbf{4 4 \%}$ & $16 \%$ & & \\
UK & $\mathbf{6 7 \%}$ & $32 \%$ & $\mathbf{5 3 \%}$ & $-8 \%$ & $\mathbf{7 6 \%}$ & \\
US & $34 \%$ & $28 \%$ & $27 \%$ & $26 \%$ & $16 \%$ & $15 \%$ \\
\hline
\end{tabular}

Panel C. Correlation for regression residuals from the Hendry model

\begin{tabular}{ccccccc}
\hline & CANADA & FRANCE & GERMANY & ITALY & JAPAN & UK \\
\hline FRANCE & $38 \%$ & & & & & \\
GERMANY & $\mathbf{5 2 \%}$ & $-22 \%$ & & & & \\
ITALY & $3 \%$ & $\mathbf{6 6 \%}$ & $-37 \%$ & & & \\
JAPAN & $34 \%$ & $37 \%$ & $\mathbf{4 7 \%}$ & $22 \%$ & & \\
UK & $\mathbf{7 1 \%}$ & $33 \%$ & $\mathbf{5 4 \%}$ & $2 \%$ & $\mathbf{6 3 \%}$ & \\
US & $30 \%$ & $27 \%$ & $37 \%$ & $20 \%$ & $13 \%$ & $12 \%$ \\
\hline
\end{tabular}


Figure 1. Idiosyncratic variances over time

In Panel A, we plot the time-series idiosyncratic variance for the U.S. sample. The sample period is January 1964 to December 2008. In Panels B and C, we plot the time-series idiosyncratic variances for $\mathrm{G} 7$ countries. The aggregate idiosyncratic variance measures using CLMX and FF are defined in equations (2) and (4), respectively. The U.S. return data are obtained from CRSP, and the return data for other countries are obtained from DataStream. All the returns are denominated in U.S. dollars. All variance time-series statistics are annualized.

Panel A. U.S. (daily data)

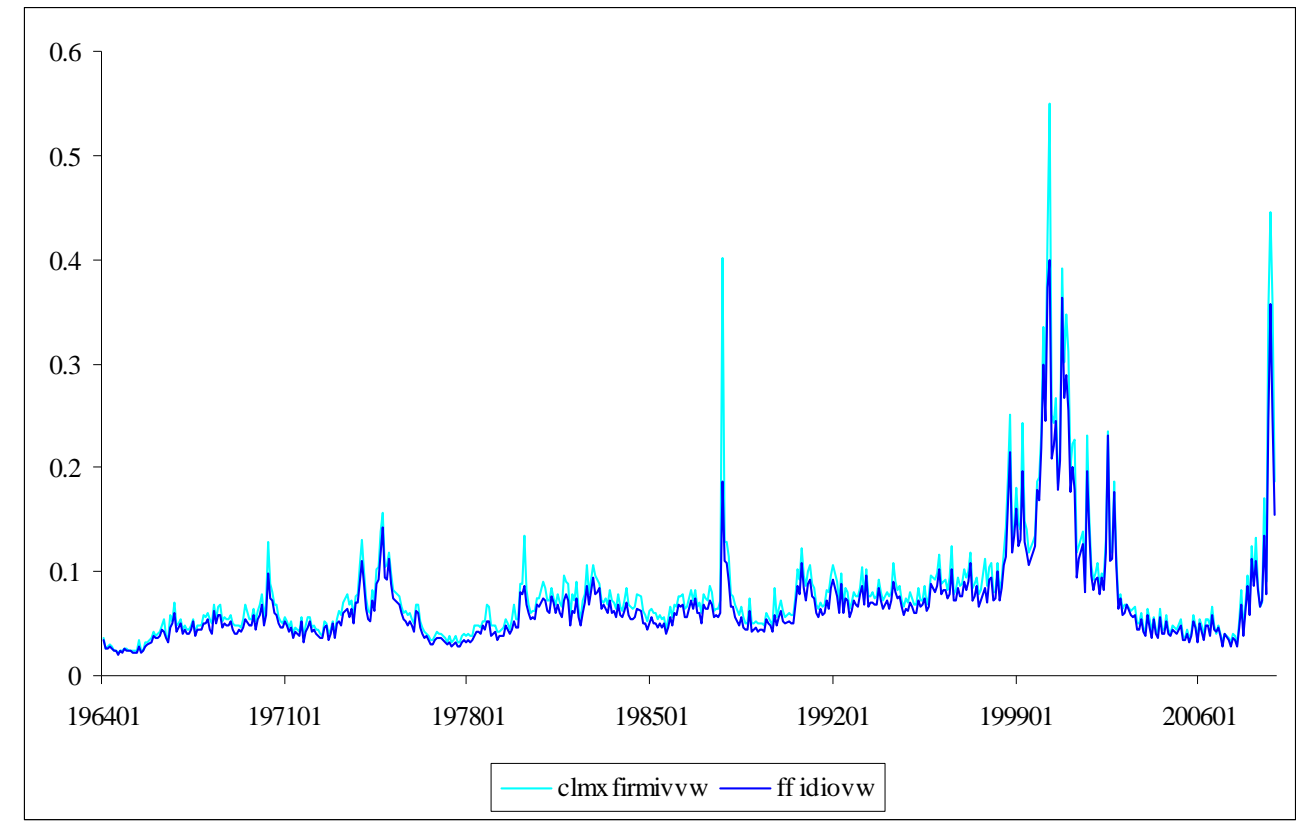

Panel B. G7 (daily data, CLMX)

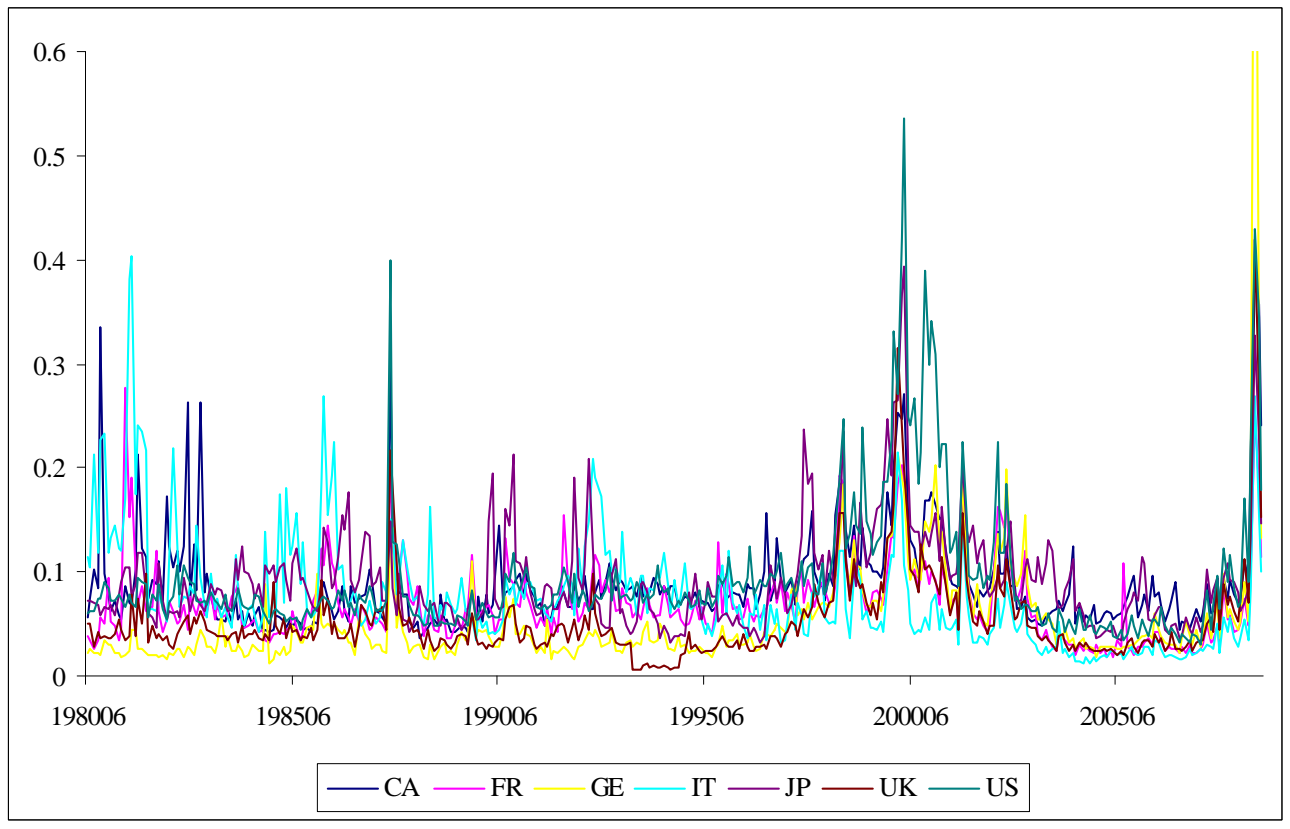


Figure 2. Regime probabilities for U.S. idiosyncratic variances

This figure reports the smoothed probability of being in regime 2 for the U.S., using a regime switching model defined in equations (6) and (7). The model is estimated over sample period 1964 - 2008. The variables $\sigma_{C L M X}^{2}$ and $\sigma_{F F}^{2}$ are the aggregate firm level idiosyncratic variances, as defined in equations (2) and (4), respectively.

Panel A. $\sigma_{\text {CLMX }}^{2}$

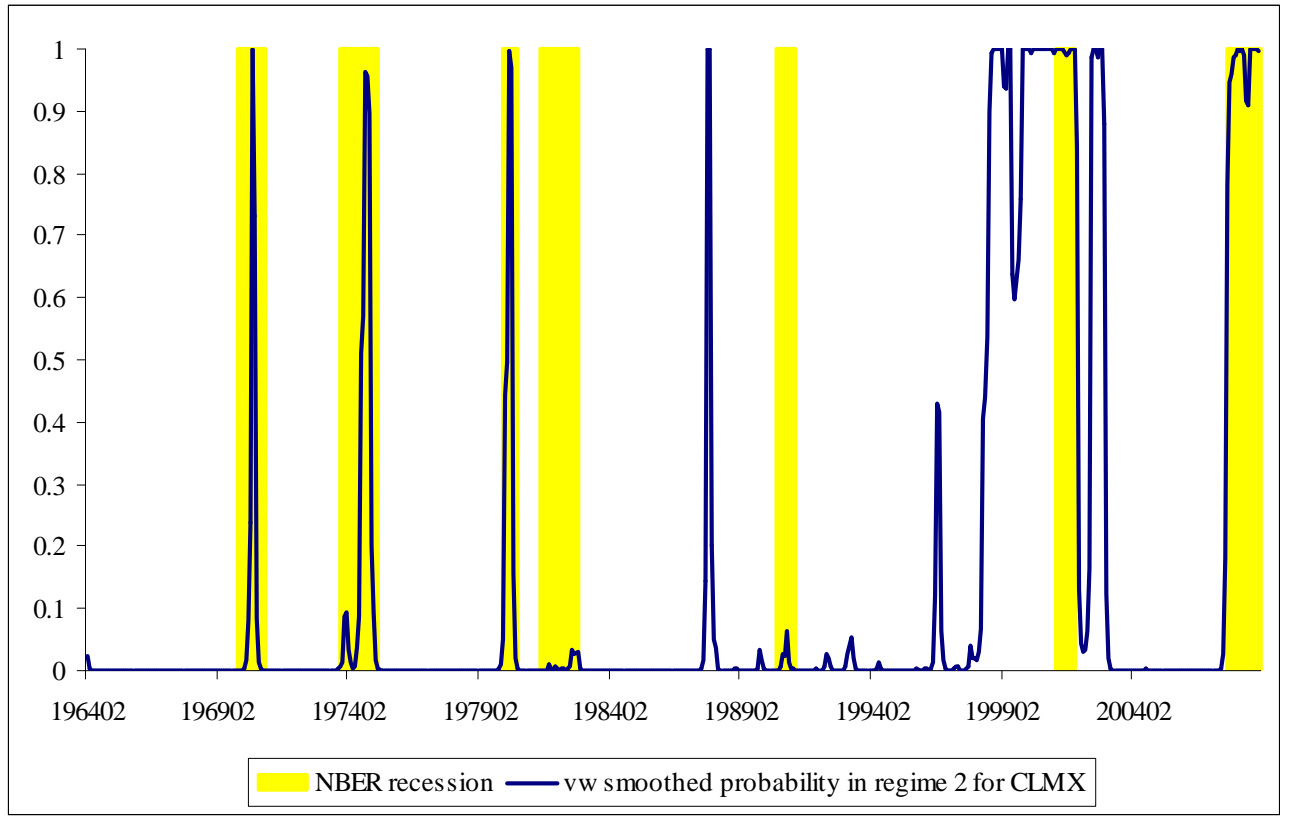

Panel B. $\sigma_{F F}^{2}$

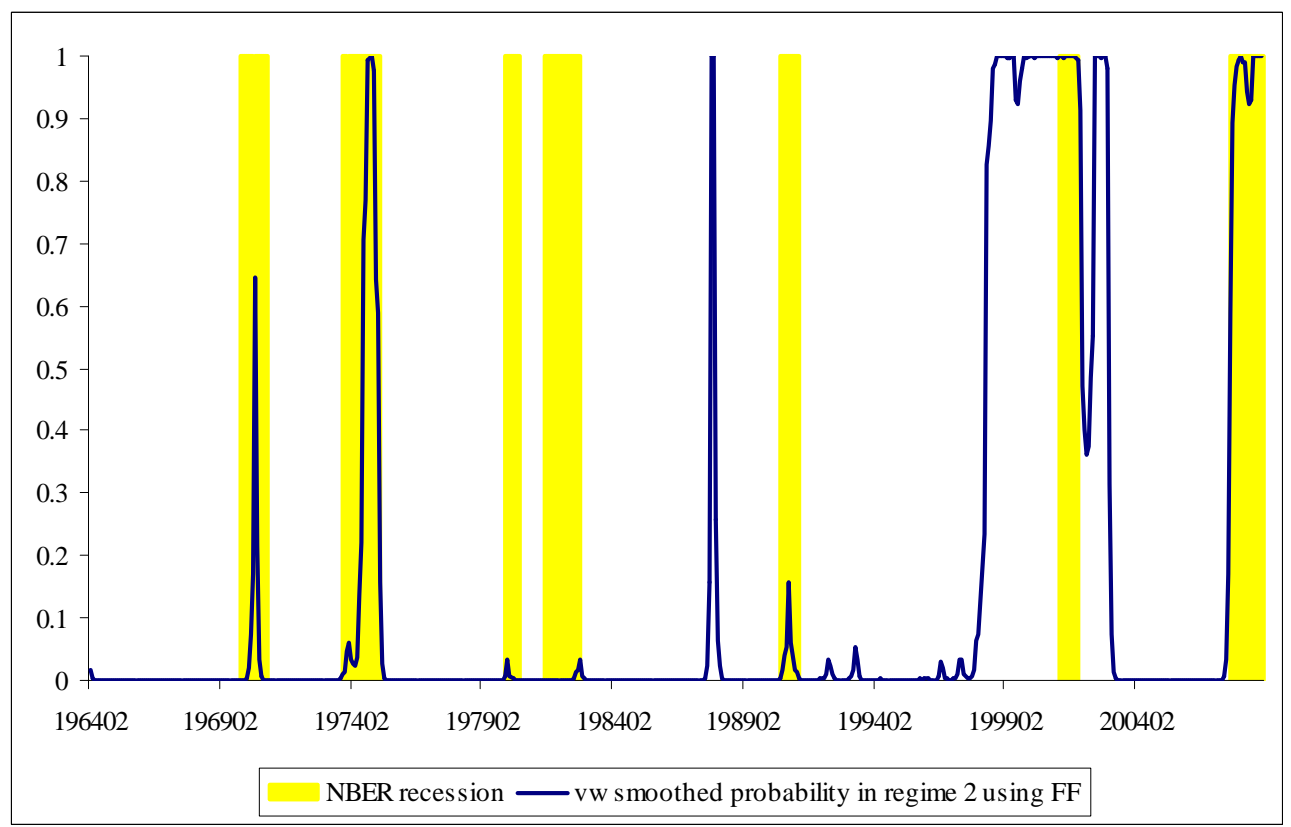


Figure 3. Recursive trend tests for the U.S.

This figure reports the t-dan test statistics for the U.S., which is estimated for a sample period starting in 1964:01 and ending between 1970:04 (the first high variance regime) and 2008:12. The variable $\sigma_{C L M X}^{2}$ is the annualized aggregate firm level idiosyncratic variance computed using daily data, as defined in equation (2). The horizontal line at 2.05 represents the critical value for the trend test (t-dan test) to be significant at $5 \%$.

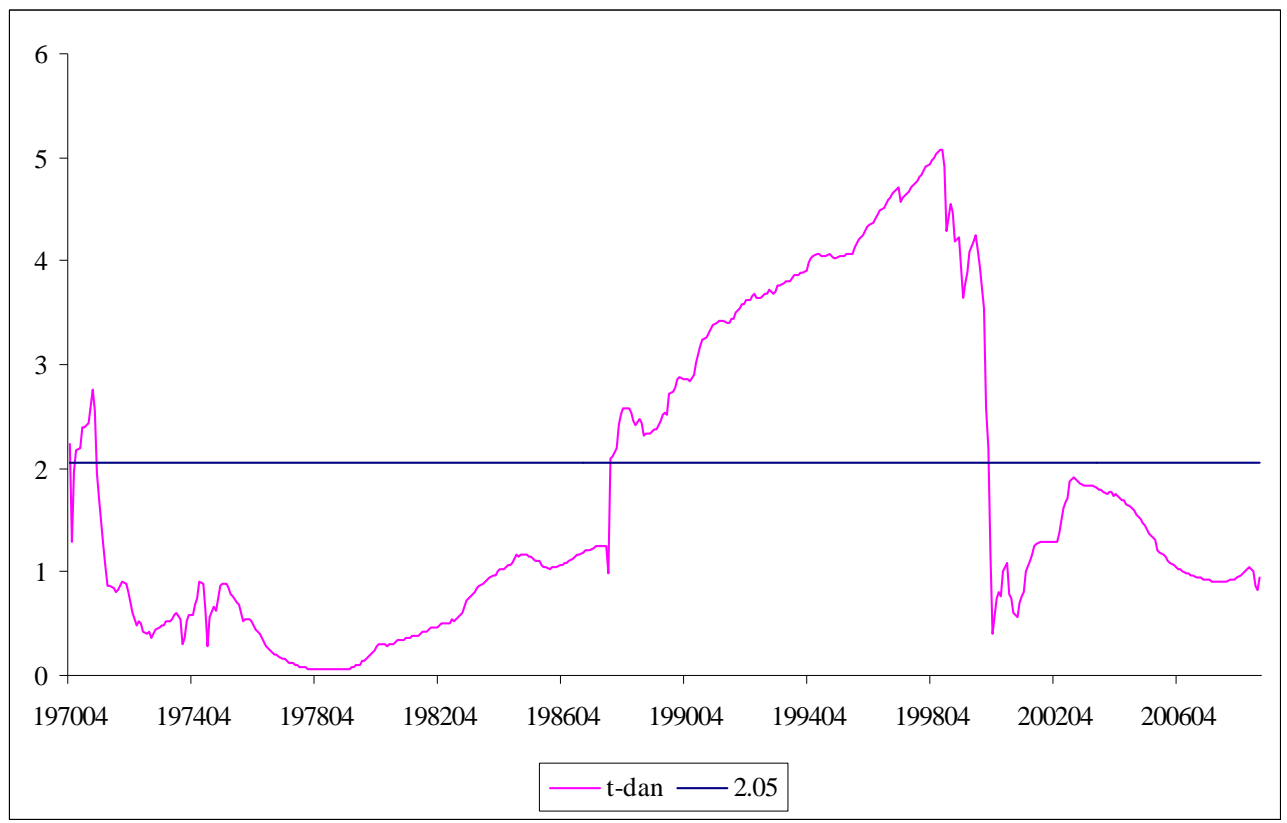




\section{Appendix}

\section{Robustness}

\subsection{Weekly International Data and Alternative Risk Specification}

We consider an alternative risk model using both global and local factors. Since the global factors are constructed with data from different countries, and due to the well-known nonsynchronous trading problem, we estimate this model using weekly data.

We calculate firm idiosyncratic volatilities according to a modified Fama-French type model that we call WLFF (for Fama-French model with world and local factors), as in BHZ (2009). The model has six factors, a global market factor $(W M K T)$, a global size factor (WSMB), a global value factor $(W H M L)$, a local market factor $(L M K T)$, a local size factor $(L S M B)$ and a local value factor $(L H M L)$ :

$$
\begin{aligned}
R_{j, t}= & b_{0, j, s}+b_{1, j, s} W M K T_{t}+b_{2, j, s} W S M B_{t}+b_{3, j, s} W H M L_{t} \\
& +b_{4, j, s} L M K T_{t}+b_{5, j, s} L S M B_{t}+b_{6, j, s} L H M L_{t}+u_{j, t}^{W L F F} .
\end{aligned}
$$

where week $t$ belongs to a six-month period $s$. To allow for time-varying betas, the above model is re-estimated every six months with weekly data. The combination of local and global factors with time-varying betas makes the model flexible enough to fit stock market comovements in an environment where the degree of global market integration may change over time. The local factors are in fact regional factors, where we consider three regions: North America, Europe and the Far East. The global market factor, $W M K T$, is calculated as the demeaned value-weighted sum of returns on all stocks. To calculate $W S M B$, we first compute $S M B(k)$ for each country $k$, which is the difference between the value-weighted returns of the smallest $30 \%$ of firms and the largest $30 \%$ of firms within country $k$. Factor $W S M B$ is the demeaned value weighted sum of individual country $S M B(k)$ s. Factor $W H M L$ is calculated in a similar manner as the demeaned value weighted sum of individual country $H M L(k)$ s using high versus low book-to-market values. The local factors $(L M K T, L S M B, L H M L)$ are all orthogonalized relative to the global factors (WMKT, WSMB,$W H M L)$. BHZ (2009) show that this model fits the comovements between country-industry portfolios and country-style portfolios very well, and it also captures firm level comovements well. 
We calculate the idiosyncratic variance for stock $j$ as the variance of the residual of the regression, that is, $\sigma^{2}\left(u_{j, t}^{W L F F}\right)$, and we then aggregate to the country level:

$$
\sigma_{W L F F, s}^{2}=\sum_{j=1}^{N} w_{j, s} \sigma^{2}\left(u_{j, t}^{W L F F}\right),
$$

where week $t$ belongs to the six-month period $s$. The weight $w_{j, s}$ is computed from firm $j$ 's relative market capitalization at the end of the last six-month period, and $N$ represents the number of firms within one country.

Table A1 Panel A reports trend test results for the 23 developed countries. We fail to detect a significant time trend for any country, using either the t-dan test or the t-ps1 test.

\subsection{Equal Weighting}

In Panels B and C of Table A1, we examine the time-series behavior of equally weighted idiosyncratic variances. We focus on the U.S. idiosyncratic variance over 1964 - 2008, computed from daily data. Since the results for the other developed countries are very similar, we do not report those to save space. In Panel B, the time-series mean of the equal-weighted CLMX (FF) idiosyncratic variance is 0.4308 (0.3530), which is much larger than its value-weighted counterpart of 0.0800 (0.0697). Obviously, the returns of smaller firms are much more volatile. In Panel C, we report the Vogelsang trend test results. Interestingly, the equally weighted idiosyncratic variance time series shows a larger trend coefficient than the value-weighted time series, but the coefficient is now insignificantly different from zero for all cases, even for the 1964-1997 period. This, in fact, confirms the results in CLMX. Equally weighted idiosyncratic variances are too noisy to allow strong statistical inference.

\subsection{Subsamples}

In Panel D, we report trend test results for different groups of stocks. We first separate firms based on the listing exchange: NYSE/AMEX vs. Nasdaq. Next, we separate large/small firms using the median NYSE market cap; we separate old/young firms using the median firm age; and we separate high price/low price stocks using $\$ 10$ as a benchmark.

For the 1964-1997 samples, we mostly confirm the results in BCL, finding trends for most sub-groups but not for the NYSE stocks. For the longer sample, we fail to reject the null of "no trend" for all subgroups. 


\section{Residual specification tests}

\subsection{The tests}

We apply the specification test to three models:

$$
\begin{aligned}
A R(1) & : y_{t}=b_{0}+b_{1} y_{t-1}+e_{t}^{A R}, \\
\operatorname{GARCH}(1,1) & : y_{t}=b_{0}+b_{1} y_{t-1}+e_{t}^{G A R C H}, \\
h_{t} & =\sigma_{t \mid t-1}^{2}\left(e_{t}^{G A R C H}\right)=w+c_{0} h_{t-1}+c_{1}\left(e_{t-1}^{G A R C H}\right)^{2}, \\
R S & : \quad y_{t}=\left(1-b_{i}\right) \mu_{i}+b_{i} y_{t-1}+\sigma_{i} e_{t}^{R S}, i=1,2,
\end{aligned}
$$

where $y_{t}$ is the variable of interest. In the estimation, all error terms are assumed to be normally distributed. We examine specification tests for the residuals, $e_{t}$, which should have the following first order moment conditions:

$$
\begin{aligned}
E\left(e_{t}\right) & =0, \\
E\left(e_{t} e_{t-1}\right) & =0 .
\end{aligned}
$$

Because $e_{t}$ is forced to have mean zero in the autoregressive specification, but may not have zero mean in other specifications, we work with demeaned residuals. For second order moments, we have

$$
E\left(e_{t}^{2}\right)-\sigma_{t \mid t-1}^{2}\left(e_{t}\right)=0
$$

where $\sigma_{t \mid t-1}^{2}=\operatorname{var}\left(e_{t}\right)$ for the $\operatorname{AR}(1)$ model, and $\sigma_{t \mid t-1}^{2}=h_{t}$ for the $\operatorname{GARCH}(1,1)$ model. Moreover, the serial correlation of the squared residuals also ought to be zero, for which we use

$$
E\left[\left(e_{t}^{2}-\sigma_{t \mid t-1}^{2}\right)\left(e_{t-1}^{2}-\sigma_{t-1 \mid t-2}^{2}\right)\right]=0
$$

Finally, we test the correct specification of the higher order moments for the residuals. For skewness, we have

$$
E\left[e_{t}^{3}-\left(\sigma_{t \mid t-1}^{2}\right)^{3 / 2}\right]=0
$$

for kurtosis, we have

$$
E\left[e_{t}^{4}-\left[\sigma_{t \mid t-1}^{2}\right]^{2}\right]=0
$$

The calculations are more complicated for the RS model. We start by computing the residuals conditioning on the $t-1$ information in an obvious manner: 


$$
e_{t}^{R S}=y_{t}-E\left(y_{t} \mid t-1\right)=y_{t}-p_{1}\left[\left(1-b_{1}\right) \mu_{1}+b_{1} y_{t-1}\right]-p_{2}\left[\left(1-b_{2}\right) \mu_{2}+b_{2} y_{t-1}\right]
$$

where $p_{1}$ denotes the probability of being in regime 1 , and $p_{2}$ the probability of being in regime 2. We compute residuals using ex-post (smoothed) probabilities.

To shorten future formulas, we define

$$
\begin{aligned}
y_{t \mid t-1} & =E\left(y_{t} \mid t-1\right) \\
& =p_{1}\left[\left(1-b_{1}\right) \mu_{1}+b_{1} y_{t-1}\right]+p_{2}\left[\left(1-b_{2}\right) \mu_{2}+b_{2} y_{t-1}\right], \\
k_{1} & =\left(1-b_{1}\right) \mu_{1}+b_{1} y_{t-1}-y_{t \mid t-1}, \\
k_{2} & =\left(1-b_{2}\right) \mu_{2}+b_{2} y_{t-1}-y_{t \mid t-1},
\end{aligned}
$$

The conditional variance is as follows,

$$
\sigma_{t \mid t-1}^{2}=p_{1} \sigma_{1}^{2}+p_{2} \sigma_{2}^{2}+p_{1} k_{1}^{2}+p_{2} k_{2}^{2}
$$

Now we can compute the moment conditions (7) through (9) as before.

The formulas for the unscaled skewness and kurtosis are in Timmermann (2000) and become, for our model:

$$
\begin{aligned}
\text { skew }_{t \mid t-1} & =\left[p_{1}\left(3 \sigma_{1}^{2} k_{1}+k_{1}^{3}\right)+p_{2}\left(3 \sigma_{2}^{2} k_{2}+k_{2}^{3}\right)\right] \\
\text { kurt }_{t \mid t-1} & =\left[p_{1}\left(3 \sigma_{1}^{4}+k_{1}^{4}+6 \sigma_{1}^{2} k_{1}^{2}\right)+p_{2}\left(3 \sigma_{2}^{4}+k_{2}^{4}+6 \sigma_{2}^{2} k_{2}^{2}\right)\right]-3\left(\sigma_{t \mid t-1}^{2}\right)^{2} .
\end{aligned}
$$

Consequently, the last two moment conditions are,

$$
\begin{aligned}
E\left[\left(e_{t}^{R S}\right)^{3}-s k e w_{t \mid t-1}\right] & =0, \\
E\left[\left(e_{t}^{R S}\right)^{4}-k u r t_{t \mid t-1}\right] & =0 .
\end{aligned}
$$

To test all moment conditions jointly, we always use a Newey-West (1987) covariance matrix with 12 lags.

\subsection{Empirical Results}

It is important to verify that a RS model indeed fits the data well, and that it fits the data better than simpler alternative models. We conduct a number of specification tests on the residuals of various RS models, and we report tests for two alternative benchmark models: an AR(1) model in 
levels with Gaussian shocks, and an $\operatorname{AR}(1)$ model with a $\operatorname{GARCH}(1,1)$ volatility process. Our tests examine 6 moment conditions: the mean and one auto-correlation of the residuals; the variance and one auto-correlation of the squared residuals; and the third and fourth order moments. Section 2.1 of this appendix details the tests. While we use asymptotic critical values, it is quite likely that our tests over-reject in small samples. This is particularly true if the data are actually generated from a non-linear RS model (see e.g. Baele, Bekaert and Inghelbrecht (2010)).

Table A.2 reports the results. The three panels investigate, respectively, the mean and variance specification; the higher moments conditions; and finally in Panel C, a joint test. For the RS models, we use smoothed ex-post probabilities to infer residuals and model moments. We present both the long sample for U.S. for the two risk models and the short sample for all countries. Focusing on the joint test first, the regime switching model clearly outperforms the two other models. Over the 9 tests, there is not a single $1 \%$ rejection, and only three $5 \%$ rejections (for Canada, Germany and the UK). The AR model on the other hand is always rejected at the $1 \%$ level, whereas the GARCH model features only two cases for which it is not rejected at the $5 \%$ level (short sample U.S., and long sample U.S. when the FF model is used). The sources of the rejections differ across countries, and in some cases the joint test simply adds power to the two sub-tests.

In unreported work, we also apply the three models to the logarithm of the variance. Such a model keeps the variance everywhere positive and the non-linear transformation may sufficiently reduce the outliers in the data to make the idiosyncratic variance process more amenable to linear modeling. However, none of the models performs better in logarithmic form, so that we restrict further analysis to the untransformed variances.

\section{Accounting Data Details}

In this appendix, we describe how we construct the accounting data variables as in Table 5 .

All return on equity (ROE) related variables are computed as in Wei and Zhang (2006), where the variable "vwroe" is the value weighted average of firm level return on equity; the variable "vwvroe" is the value weighted average of the 12-quarter time-series variance of firm level return on equity, and the variable "cvroe" is the cross-sectional variance of the firm level return on equity.

Irvine and Pontiff (2008) focus on competition measures. We follow their procedure and compute "veps" as the cross-sectional variance of shocks to earnings per share (EPS). The shocks 
to EPS are computed using a pooled auto-regressive regression of year-to-year changes in quarterly EPS. To be more specific, the dependent variable is the annual difference in earnings per share, $E P S(t)-E P S(t-4)$, at the firm level, where $t$ is current quarter, and the independent variables are $\operatorname{EPS}(t-1)-E P S(t-5), E P S(t-2)-E P S(t-6)$, and $E P S(t-3)-E P S(t-7)$. This regression attempts to adjust for seasonality in the EPS data. By computing the cross-sectional variance, this approach implicitly adjusts for the market average level of shocks to EPS, in the same spirit of "cvroe". We also compute industry turnover as the cross-sectional average at firm level for industry entries and exits each month.

Cao, Simin and Zhao (2007) consider growth options as an explanation. The most successful variable in their paper is "maba", the value weighted average of firm level market assets over book assets. We also compute "vmaba" as the value weighted average of the 12-quarter timeseries variance of firm level market assets over book assets. Following the same reasoning as for "cvroe" and "veps", we also compute "cvmaba" as the cross-sectional variance of firm level market assets over book assets.

For the $R \& D$ expenditure variables, quarterly data on $R \& D$ is not reported by the majority of firms in U.S. So we rely on annual data on R\&D. Following Comin and Mulani (2006), for each quarter, we take the corresponding fiscal year R\&D, and then divide by the quarter's total revenues (sales). We also compute the cross-sectional dispersion in R\&D (denoted cvrd) across firms each quarter, and it has a correlation of $80 \%$ with R\&D expenditures.

Notice that all U.S. accounting data are from Compustat, and thus they are quarterly data on a firm-by-firm basis. However, because firms have different fiscal year end's, the data are spread out over the year. To ensure that each month represents the full sample of firms, we follow the procedure in Irvine and Pontiff (2008) and for each month average the accounting measures of that month and the previous two months. We apply the same methodology to all quarterly accounting data.

For the international data, we compute ROE, maba, and competition related variables as we do for U.S. firms. The variable "vwroe" is the value weighted average of the annual firm level return on equity; the variable "vwvroe" is the value weighted average of the 3-year time-series variance of the annual firm level return on equity, and one variable "cvroe" is the cross-sectional variance of the firm level return on equity each year. We compute "veps" as the cross-sectional variance of shocks to annual earnings per share, where the shocks are estimated using a pooled 
regression within each country. To be more specific for the pooled regression, the dependent variable becomes $\operatorname{EPS}(t)-E P S(t-1)$, where $t$ is current year, and the independent variable is $E P S(t-1)-E P S(t-2)$. The variable "maba" is the value weighted average of the annual firm level market assets over book assets. We also compute "vmaba" as the value weighted average of the 3-year time-series variance of annual firm level market assets over book assets, and "cvmaba" as the cross-sectional variance of annual firm level market assets over book assets.

\section{Hendry Regressions}

We also use a model reduction techniques inspired by Hendry and Krolzig's (2001) PCGets ("general-to-specific") system. We first run a regression using all possible regressors (21 in total). We then verify the joint significance of all the variables that are not significant at the $10 \%$ level. The joint test also uses a $10 \%$ significance level. If the joint test fails to reject that a set of variables is insignificant, we eliminate these variables from the regression and then run one final regression with the remaining variables. However, if the set of variables is jointly significant, we increase the significance level by $5 \%$ for both the individual and joint tests. The results are reported in Table A3. We end up using a 10\% significance level.

The model is less parsimonious than the subgroup model reported in the paper, as it retains 14 variables, all significant at the $1 \%$ level except for industry turnover, which is significant at $5 \%$ level. After eliminating the useless variables, the adjusted $R^{2}$ remains unchanged at $86 \%$, and the coefficients of the retained variables remain similar to what they were in the full model. Interestingly, the signs for the compositional variables "psmall" (the relative importance of small firms) and "pyoung" (the relative importance of young firms) are now as expected. However, psmall contributes a negative $13 \%$ to the explained variation, whereas psmall's contribution is about $12 \%$. Together, they explain nothing. General turnover does enter significantly and explains about $10 \%$ of the total explained variation. The four corporate variables retained in the subgroup model survive here too with about the same economic and statistical significance. Two additional corporate variables are retained as well (earnings variability, veps, and the cross-sectional variance

of the return on equity, cvroe). While veps explains $7 \%$ of the variation in idiosyncratic variances, cvroe's contribution is a negative 11\%. Maba (growth options) remains very important with a $44 \%$ contribution to the overall variance of the fitted value. As for the business cycle variables, the variance premium, the term spread and the confidence index are the additional business variables 
in the final model. The term spread and confidence index are not economically important, but the variance premium accounts for $10 \%$ of the explained variation. Its coefficient is in line with expectations. The default spread is no longer significant, but industrial production and the total market variance still are. They have similar coefficients as they do in the subgroup model, and similar economic significance as well, with the market variance now contributing $32 \%$ of the total explained variation.

\section{Other Tables}

The Tables A4 to A6 and Figure A1 depict results and analysis that is adequately summarized in the main text. 
Table A1. Robustness checks: global model idiosyncratic volatilities and equal weighted idiosyncratic variances

Panel A reports trend test results for 23 countries idiosyncratic volatilities time series, using the Vogelsang (1998) t-PS1 test and the Bunzel and Vogelsang (2008) t-dan test. The 5\% critical value (two sided) for t-dan is 2.052, and for t-ps1 is 2.152. The variable $\sigma_{W L F F}^{2}$ is the aggregate firm level idiosyncratic variances, as defined in equation (1) in the appendix. In Panel B, we report summary statistics for equally weighted aggregate idiosyncratic volatilities for the U.S. sample, and the sample period is January 1964 to December 2008. In Panel C, we report trend test results for U.S. idiosyncratic variance time-series, using the trend tests described above. We report results for both $\sigma_{C L M X}^{2}$ and $\sigma_{F F}^{2}$. In Panel D, we report trend test results for different groups of stocks, using $\sigma_{\text {CLMX }}^{2}$. We separate large/small firms using median NYSE market cap; we separate old/young firms using median firm age; and we separate high price/low price stocks using \$10 as a benchmark. We compute idiosyncratic variances using the CLMX and FF model. In Panels A, C and D, we use a pre-whitened model for the t-dan test. Coefficients in Panels A, C and $\mathrm{D}$ are multiplied by 100 . All variance time-series statistics are annualized.

Panel A. Trend test for WLFF model idiosyncratic volatilities

\begin{tabular}{l|cccc}
\hline & & & $\sigma_{\text {WLFF }}^{2}$ & \\
& b-dan & t-dan & b-ps1 & t-ps1 \\
\hline CANADA & 0.218 & 0.07 & 0.234 & 0.16 \\
FRANCE & -1.495 & -0.18 & -1.294 & -0.44 \\
GERMANY & 1.019 & 0.01 & 1.089 & 0.10 \\
ITALY & -2.566 & -0.91 & -2.212 & -1.08 \\
JAPAN & 0.234 & 0.02 & 0.223 & 0.07 \\
U.K. & -0.154 & -0.01 & -0.120 & -0.04 \\
U.S. & 0.003 & 0.00 & 0.255 & 0.03 \\
AUSTRALIA & -0.732 & -0.03 & -1.089 & -0.36 \\
AUSTRIA & 1.533 & 0.47 & 1.756 & 0.66 \\
BELGIUM & -0.705 & 0.00 & -0.866 & -0.06 \\
DENMARK & -0.693 & -0.04 & -0.682 & -0.16 \\
FINLAND & -1.951 & -0.01 & -1.909 & -0.07 \\
GREECE & -1.877 & -0.05 & -1.673 & -0.19 \\
HK & -0.669 & -0.36 & -0.778 & -0.55 \\
IRELAND & 0.180 & 0.01 & -0.337 & -0.06 \\
NETHERLANDS & 0.261 & 0.01 & 0.295 & 0.06 \\
NEW ZEALAND & -1.683 & -0.33 & -1.798 & -0.82 \\
NORWAY & -0.805 & -0.59 & -0.975 & -1.33 \\
PORTUGAL & -3.383 & -0.12 & -4.344 & -0.77 \\
SINGAPORE & 0.049 & 0.01 & -0.001 & 0.00 \\
SPAIN & -2.733 & -0.16 & -3.007 & -0.71 \\
SWEDEN & -0.748 & -0.40 & -0.514 & -0.35 \\
SWITZERLAND & 0.526 & 0.04 & 0.759 & 0.19 \\
\hline
\end{tabular}


Panel B. Summary statistics for the U.S. equally weighted idiosyncratic variances

\begin{tabular}{c|cc|cc}
\hline & \multicolumn{2}{|c|}{$\sigma_{\text {CLMX }}^{2}$} & \multicolumn{2}{c}{$\sigma_{F F}^{2}$} \\
$\mathrm{~N}$ & Mean & Std & Mean & Std \\
\hline 540 & 0.4308 & 0.3036 & 0.3530 & 0.2436 \\
\hline
\end{tabular}

Panel C. Trend test for the U.S. equally weighted idiosyncratic variances

\begin{tabular}{c|cccc|cccc}
\hline & \multicolumn{4}{|c|}{$1964-1997$} & \multicolumn{4}{c}{$1964-2008$} \\
\hline & b-dan & t-dan & b-ps1 & t-ps1 & b-dan & t-dan & b-ps1 & t-ps1 \\
\hline$\sigma_{C L M X}^{2}$ & 0.154 & 1.20 & 0.135 & 0.87 & 0.109 & 0.23 & 0.142 & 0.71 \\
$\sigma_{F F}^{2}$ & 0.132 & 0.52 & 0.116 & 0.59 & 0.088 & 0.17 & 0.118 & 0.60 \\
\hline
\end{tabular}

Panel D. Trend test for the U.S. subsamples using $\sigma_{\text {CLMX }}^{2}$

\begin{tabular}{l|cccc|cccc}
\hline & \multicolumn{5}{|c|}{$1964-1997$} & \multicolumn{4}{c}{$1964-2008$} \\
\hline & b-dan & t-dan & b-ps1 & t-ps1 & b-dan & t-dan & b-ps1 & t-ps1 \\
\hline Nasdaq & 0.051 & 4.32 & 0.053 & 2.93 & 0.025 & 0.54 & 0.047 & 0.96 \\
NYSE/AMEX & 0.002 & 0.79 & 0.003 & 0.67 & 0.007 & 0.52 & 0.006 & 0.71 \\
Large & 0.006 & 2.68 & 0.006 & 1.77 & 0.012 & 0.82 & 0.012 & 1.02 \\
Small & 0.039 & 3.54 & 0.031 & 1.51 & 0.047 & 0.71 & 0.054 & 1.01 \\
Old & 0.007 & 3.14 & 0.008 & 2.26 & 0.009 & 0.81 & 0.010 & 1.24 \\
Young & 0.031 & 5.23 & 0.028 & 3.74 & 0.034 & 0.81 & 0.043 & 1.22 \\
High price & 0.008 & 3.45 & 0.007 & 2.43 & 0.012 & 0.94 & 0.013 & 1.19 \\
Low price & 0.080 & 3.68 & 0.064 & 1.27 & 0.068 & 0.79 & 0.085 & 1.07 \\
\hline
\end{tabular}


Table A2. Regime switching model specification tests

AR stands for a first-order autoregressive model with homoskedastic errors. GARCH is the AR model with the variance of the error term following a GARCH(1,1) process. RS stands for the regime switching model discussed in the text. The moment conditions for RS models are computed following Timmermann (2000). We use smoothed ex-post regime probabilities to compute moments. In Panel A, we use 4 moments: mean, variance, and first order autocorrelations for both. In Panel B, we consider 2 moments: skewness and kurtosis. In Panel C, we combine the 6 moments in Panels A and B. To compute the p-values of the Wald tests, we always use 12 Newey-West lags to adjust for serial correlation.

Panel A. Mean, variance and auto-correlations

\begin{tabular}{|c|c|c|c|c|c|c|c|c|c|c|c|c|c|c|c|c|c|c|}
\hline & $\begin{array}{l}\text { US } \\
\text { long }\end{array}$ & & US long & & CA & & FR & & GE & & IT & & JP & & UK & & US & \\
\hline & CLMX & & FF & & CLMX & & CLMX & & CLMX & & CLMX & & CLMX & & CLMX & & CLMX & \\
\hline & Wald & $\mathrm{p}$ & Wald & $\mathrm{p}$ & Wald & $\mathrm{p}$ & Wald & $\mathrm{p}$ & Wald & $\mathrm{p}$ & Wald & $\mathrm{p}$ & Wald & $\mathrm{p}$ & Wald & $\mathrm{p}$ & Wald & $\mathrm{p}$ \\
\hline AR & 14.902 & $0.5 \%$ & 24.566 & $0.0 \%$ & 15.425 & $0.4 \%$ & 6.432 & $16.9 \%$ & 23.428 & $0.0 \%$ & 13.834 & $0.8 \%$ & 10.323 & $3.5 \%$ & 7.353 & $11.8 \%$ & 11.250 & $2.4 \%$ \\
\hline GARCH & 9.317 & $5.4 \%$ & 5.961 & $20.2 \%$ & 14.643 & $0.6 \%$ & 9.738 & $4.5 \%$ & 2.382 & $66.6 \%$ & 14.158 & $0.7 \%$ & 11.100 & $2.6 \%$ & 5.319 & $25.6 \%$ & 5.078 & $27.9 \%$ \\
\hline RS & 7.037 & $13.4 \%$ & 7.088 & $13.1 \%$ & 4.639 & $32.6 \%$ & 1.251 & $87.0 \%$ & 9.526 & $4.9 \%$ & 5.381 & $25.0 \%$ & 0.849 & $93.2 \%$ & 0.456 & $97.8 \%$ & 3.336 & $50.3 \%$ \\
\hline
\end{tabular}

Panel B. Skewness and kurtosis

\begin{tabular}{|c|c|c|c|c|c|c|c|c|c|c|c|c|c|c|c|c|c|c|}
\hline \multicolumn{19}{|c|}{ US } \\
\hline & long & & US long & & CA & & FR & & GE & & IT & & JP & & UK & & US & \\
\hline & CLMX & & $\mathrm{FF}$ & & CLMX & & CLMX & & CLMX & & CLMX & & CLMX & & CLMX & & CLMX & \\
\hline & Wald & $\mathrm{p}$ & Wald & $\mathrm{p}$ & Wald & $\mathrm{p}$ & Wald & $\mathrm{p}$ & Wald & $\mathrm{p}$ & Wald & $\mathrm{p}$ & Wald & $\mathrm{p}$ & Wald & $\mathrm{p}$ & Wald & $\mathrm{p}$ \\
\hline AR & 3.709 & $15.7 \%$ & 3.898 & $14.2 \%$ & 6.458 & $4.0 \%$ & 10.823 & $0.5 \%$ & 5.699 & $5.8 \%$ & 9.280 & $1.0 \%$ & 7.159 & $2.8 \%$ & 6.089 & $4.8 \%$ & 4.259 & $11.9 \%$ \\
\hline GARCH & 3.493 & $17.4 \%$ & 3.795 & $15.0 \%$ & 5.297 & $7.1 \%$ & 4.706 & $9.5 \%$ & 1.110 & $57.4 \%$ & 6.247 & $4.4 \%$ & 9.602 & $0.8 \%$ & 2.914 & $23.3 \%$ & 3.203 & $20.2 \%$ \\
\hline RS & 2.432 & $29.6 \%$ & 4.656 & $9.8 \%$ & 5.362 & $6.9 \%$ & 2.763 & $25.1 \%$ & 9.487 & $0.9 \%$ & 5.509 & $6.4 \%$ & 7.216 & $2.7 \%$ & 1.610 & $44.7 \%$ & 2.375 & $30.5 \%$ \\
\hline
\end{tabular}

Panel C. All

\begin{tabular}{|c|c|c|c|c|c|c|c|c|c|c|c|c|c|c|c|c|c|c|}
\hline & $\begin{array}{c}\text { US } \\
\text { long }\end{array}$ & & US long & & CA & & FR & & GE & & IT & & JP & & UK & & US & \\
\hline & CLMX & & FF & & CLMX & & CLMX & & CLMX & & CLMX & & CLMX & & CLMX & & CLMX & \\
\hline & Wald & $\mathrm{p}$ & Wald & p & Wald & $\mathrm{p}$ & Wald & $\mathrm{p}$ & Wald & p & Wald & $\mathrm{p}$ & Wald & $\mathrm{p}$ & Wald & $\mathrm{p}$ & Wald & $\mathrm{p}$ \\
\hline AR & 25.948 & $0.0 \%$ & 32.537 & $0.0 \%$ & 24.609 & $0.0 \%$ & 24.428 & $0.0 \%$ & 26.516 & $0.0 \%$ & 22.814 & $0.1 \%$ & 21.562 & $0.2 \%$ & 25.122 & $0.0 \%$ & 21.869 & $0.1 \%$ \\
\hline GARCH & 18.937 & $0.4 \%$ & 10.005 & $12.4 \%$ & 24.211 & $0.1 \%$ & 18.603 & $0.5 \%$ & 19.906 & $0.3 \%$ & 22.117 & $0.1 \%$ & 17.508 & $0.8 \%$ & 13.356 & $3.8 \%$ & 12.501 & $5.2 \%$ \\
\hline RS & 9.543 & $14.5 \%$ & 9.279 & $15.9 \%$ & 12.771 & $4.7 \%$ & 3.563 & $73.6 \%$ & 14.650 & $2.3 \%$ & 10.668 & $9.9 \%$ & 11.310 & $7.9 \%$ & 13.106 & $4.1 \%$ & 6.530 & $36.7 \%$ \\
\hline
\end{tabular}


Table A3. What drives U.S. idiosyncratic volatility? Hendry regression

OLS regressions of aggregate idiosyncratic variances in the U.S. over 1964-2008, computed using the CLMX model, on various determinants, labeled on the left. We show the regression on all variables simultaneously and a regression reduced by the general-to-specific paring down technique, described in the appendix. In the last row, we also report a joint Wald test checking whether the variables dropped from regression I to II are jointly significantly different from zero. All p-values are based on standard errors, using 12 Newey-West lags. The last column reports the covariance decomposition described in the text.

\begin{tabular}{|c|c|c|c|c|c|}
\hline & \multicolumn{2}{|c|}{ I. All variables } & \multicolumn{3}{|c|}{ II. Significant variables from I } \\
\hline & coef. & p-value & coef. & p-value & Cov decomp \\
\hline pyoung & 0.772 & 0.001 & 0.879 & 0.000 & $12 \%$ \\
\hline psmall & 11.058 & 0.007 & 13.467 & 0.000 & $-13 \%$ \\
\hline plow & -0.332 & 0.808 & & & \\
\hline lowto & -0.001 & 0.807 & & & \\
\hline dto & 0.023 & 0.003 & 0.024 & 0.009 & $10 \%$ \\
\hline vwroe & 0.086 & 0.836 & & & \\
\hline vwvroe & 1.332 & 0.733 & & & \\
\hline cvroe & -0.846 & 0.008 & -0.952 & 0.000 & $-11 \%$ \\
\hline veps & 0.009 & 0.001 & 0.007 & 0.003 & $7 \%$ \\
\hline indto & 0.003 & 0.005 & 0.004 & 0.013 & $1 \%$ \\
\hline maba & 0.093 & 0.000 & 0.101 & 0.000 & $44 \%$ \\
\hline vmaba & -0.008 & 0.148 & & & \\
\hline cvmaba & 0.000 & 0.529 & & & \\
\hline rd & 0.173 & 0.001 & 0.134 & 0.000 & $23 \%$ \\
\hline cvrd & -0.006 & 0.000 & -0.006 & 0.000 & $-8 \%$ \\
\hline mvp & 0.534 & 0.000 & 0.542 & 0.000 & $10 \%$ \\
\hline mkttv & 0.642 & 0.000 & 0.633 & 0.000 & $32 \%$ \\
\hline dip & -0.512 & 0.003 & -0.510 & 0.005 & $1 \%$ \\
\hline def & 0.004 & 0.446 & & & \\
\hline term & -0.010 & 0.000 & -0.011 & 0.000 & $2 \%$ \\
\hline confi & -0.001 & 0.000 & -0.001 & 0.000 & $-9 \%$ \\
\hline disp & -0.092 & 0.807 & & & \\
\hline Adj. R2 & $86 \%$ & & $86 \%$ & & \\
\hline Wald test & $\begin{array}{l}\text { iminate } \\
\text { p-value }\end{array}$ & $\begin{array}{c}\text { from re } \\
68.0 \%\end{array}$ & to II & & \\
\hline
\end{tabular}


Table A4. Analyzing Model Residuals

Panel A reports specification tests of the regression model residuals and residuals for a RS model on the residuals. The residuals are computed using the subgroup model and Hendry model. We conduct specification tests on the RS model residuals using both ex ante and ex post probabilities, denoted RS ante and RS post, respectively. The moment conditions include: mean, variance, autocorrelation of first order for both mean and variance, skewness and kurtosis. To compute the p-value of the Wald tests, we always use 12 Newey-West lags to adjust for serial correlation. The parameters of the RS model are reported in Panel B. We estimate the RS model as in Table 3, except we re-parameterize to ensure $0<\sigma_{1}<\sigma_{2}$. The last row in Panel B reports the Wald test of $\mu_{1}=\mu_{2}$. In Panel C, we re-estimate the subgroup and Hendry models, by allowing all coefficients to be linear functions of a dummy variable in the form of $b=b_{0}+b_{1}$ dummy. We refer to $b_{0}$ as the "constant" coefficient, and $b_{1}$ as the "dummy" coefficient. The dummy variable takes a value of 1 if the CLMX smoothed probability in regime 2 is higher than 0.5 .

Panel A. Specification test on the residuals and RS residuals of the residuals

\begin{tabular}{ccccc}
\hline Models & \multicolumn{2}{c}{ Subgroup Model } & \multicolumn{2}{c}{ Hendry Model } \\
& Wald & p-value & Wald & p-value \\
\hline residuals & 25.71 & $0.0 \%$ & 22.26 & $0.1 \%$ \\
RS post & 9.34 & $15.5 \%$ & 7.21 & $30.2 \%$ \\
\hline
\end{tabular}

Panel B. Regime switching model for the regression residuals

\begin{tabular}{c|cccc}
\hline & \multicolumn{2}{|c}{ Subgroup model } & \multicolumn{2}{c}{ Hendry model } \\
\hline & coef. & std. & coef. & std. \\
$\mu_{1}$ & -0.002 & 0.003 & -0.001 & 0.002 \\
$\mu_{2}$ & 0.009 & 0.011 & 0.006 & 0.008 \\
$b_{1}$ & 0.705 & 0.042 & 0.632 & 0.044 \\
$b_{2}$ & 0.413 & 0.121 & 0.237 & 0.136 \\
$\sigma_{1}$ & 0.013 & 0.001 & 0.012 & 0.001 \\
$\sigma_{2}$ & 0.049 & 0.005 & 0.044 & 0.005 \\
$p_{11}$ & 0.985 & 0.009 & 0.982 & 0.011 \\
$p_{22}$ & 0.929 & 0.062 & 0.903 & 0.097 \\
$\mathrm{P}\left(\mu_{1}=\mu_{2}\right)$ & $34.9 \%$ & & $42.4 \%$ & \\
\hline
\end{tabular}


Panel C. Allowing for Regime 2 Dummy in Regression Coefficients

\begin{tabular}{|c|c|c|c|c|c|c|c|c|}
\hline & \multicolumn{4}{|c|}{ Subgroup Model } & \multicolumn{4}{|c|}{ Hendry Model } \\
\hline & \multicolumn{2}{|c|}{$b_{0}$} & \multicolumn{2}{|c|}{$b_{1}$} & \multicolumn{2}{|c|}{$b_{0}$} & \multicolumn{2}{|c|}{$b_{1}$} \\
\hline & coef. & p-value & coef. & p-value & coef. & p-value & coef. & p-value \\
\hline pyoung & & & & & 0.028 & $10.5 \%$ & 0.383 & $41.4 \%$ \\
\hline psmall & & & & & 0.200 & $6.3 \%$ & 27.402 & $2.8 \%$ \\
\hline plow & & & & & & & & \\
\hline $\begin{array}{l}\text { lowto } \\
\text { dto }\end{array}$ & & & & & -0.016 & $0.4 \%$ & 0.057 & $0.0 \%$ \\
\hline \multirow{2}{*}{\multicolumn{9}{|c|}{$\begin{array}{l}\text { vwroe } \\
\text { vwvroe }\end{array}$}} \\
\hline & & & & & & & & \\
\hline cvroe & & & & & 0.390 & $0.2 \%$ & 0.754 & $43.1 \%$ \\
\hline veps & & & & & 0.000 & $73.4 \%$ & 0.016 & $0.2 \%$ \\
\hline indto & 0.003 & $2.3 \%$ & 0.003 & $48.6 \%$ & 0.002 & $0.3 \%$ & -0.004 & $47.2 \%$ \\
\hline maba & 0.066 & $0.0 \%$ & 0.067 & $0.7 \%$ & 0.058 & $0.0 \%$ & 0.087 & $0.2 \%$ \\
\hline vmaba & & & & & & & & \\
\hline \multicolumn{9}{|l|}{ cvmaba } \\
\hline rd & 0.002 & $96.9 \%$ & 0.170 & $1.7 \%$ & 0.047 & $31.0 \%$ & 0.116 & $3.8 \%$ \\
\hline cvrd & -0.003 & $0.6 \%$ & -0.003 & $20.0 \%$ & -0.002 & $3.4 \%$ & -0.011 & $0.0 \%$ \\
\hline mvp & & & & & 0.479 & $0.0 \%$ & -0.295 & $29.9 \%$ \\
\hline mkttv & 0.526 & $0.0 \%$ & 0.674 & $0.0 \%$ & 0.514 & $0.0 \%$ & 0.664 & $0.0 \%$ \\
\hline dip & -0.189 & $20.3 \%$ & -0.642 & $50.4 \%$ & -0.070 & $55.9 \%$ & -0.780 & $16.4 \%$ \\
\hline def & 0.011 & $0.5 \%$ & 0.039 & $12.7 \%$ & & & & \\
\hline term & & & & & -0.005 & $0.0 \%$ & -0.015 & $0.5 \%$ \\
\hline confi & & & & & -0.001 & $0.0 \%$ & -0.001 & $4.4 \%$ \\
\hline Adj. R2 & $89 \%$ & & & & $94 \%$ & & & \\
\hline
\end{tabular}


Table A5. Idiosyncratic volatility across G7 countries: Hendry regression

OLS regressions of aggregate idiosyncratic variances in the G7 countries over 1983-2008, computed using the CLMX model, on various determinants, labeled on the left. The annual data time series for idiosyncratic variance are averaged over monthly observations in the year. More details about the data are in the Appendix text, Section C and Table 5. We show the regression on all variables simultaneously and a regression reduced by the general-to-specific paring down technique, described in the Appendix text. In the last 4 rows, we also report joint Wald tests of whether all variables dropped step by step from regression I to II are significantly different from zero. All regressions include country dummies. All p-values are based on standard errors using 12 Newey-West lags and they are adjusted by clustering on years. All regressions include country dummies. The last column reports the covariance decomposition described in the text.

\begin{tabular}{|c|c|c|c|c|c|}
\hline & \multicolumn{2}{|c|}{ I. all variables } & \multicolumn{3}{|c|}{ II. significant variables } \\
\hline & coef. & p-value & coef. & p-value & Cov decomp \\
\hline Vwroe & -0.142 & $3.8 \%$ & -0.146 & $2.6 \%$ & $7.1 \%$ \\
\hline vwvroe & -0.498 & $43.6 \%$ & & & \\
\hline cvroe & 0.119 & $24.5 \%$ & & & \\
\hline veps & 0.039 & $6.6 \%$ & 0.050 & $0.5 \%$ & $0.1 \%$ \\
\hline indto & 0.081 & $0.8 \%$ & 0.083 & $0.6 \%$ & $0.3 \%$ \\
\hline maba & 0.024 & $0.0 \%$ & 0.024 & $0.0 \%$ & $24.6 \%$ \\
\hline vmaba & 0.002 & $2.3 \%$ & 0.002 & $2.1 \%$ & $6.7 \%$ \\
\hline cvmaba & 0.003 & $0.1 \%$ & 0.003 & $0.1 \%$ & $10.1 \%$ \\
\hline mkttv & 0.457 & $0.0 \%$ & 0.475 & $0.0 \%$ & $29.9 \%$ \\
\hline dgdp & -0.027 & $29.2 \%$ & & & \\
\hline def & 0.000 & $91.2 \%$ & & & \\
\hline term & -0.003 & $2.2 \%$ & -0.002 & $3.5 \%$ & $0.4 \%$ \\
\hline usmvp & 0.859 & $0.2 \%$ & 0.832 & $0.5 \%$ & $20.6 \%$ \\
\hline Adj. R2 & $0.71 \%$ & & $71 \%$ & & \\
\hline \multicolumn{6}{|l|}{$\mathrm{R} 2(\mathrm{w} / \mathrm{o}$} \\
\hline dummies) & $59 \%$ & & $59 \%$ & & \\
\hline \multicolumn{6}{|c|}{ Wald test for eliminating vwvroe, cvroe, dgdp, and def at $10 \%$} \\
\hline & p-value & 0.678 & & & \\
\hline
\end{tabular}


Table A6. Idiosyncratic volatility across G7 countries: beta model

OLS regressions of aggregate idiosyncratic variances in the G7 countries over 1983-2008, computed using the CLMX model, on various determinants, labeled on the left. The annual data time series for idiosyncratic variance are average over monthly observations in the year. More details about the data are in Appendix B. We show 5 regressions: one for each group of variables, one for all regressors, starting with the betas with respect to the U.S. variance, a final subgroup one based on a paring down technique selecting significant variables from the full regression. All p-values are based on standard errors using 12 Newey-West lags and are adjusted for clustering on years. The last column for the fifth regression reports the covariance decomposition described in the text.

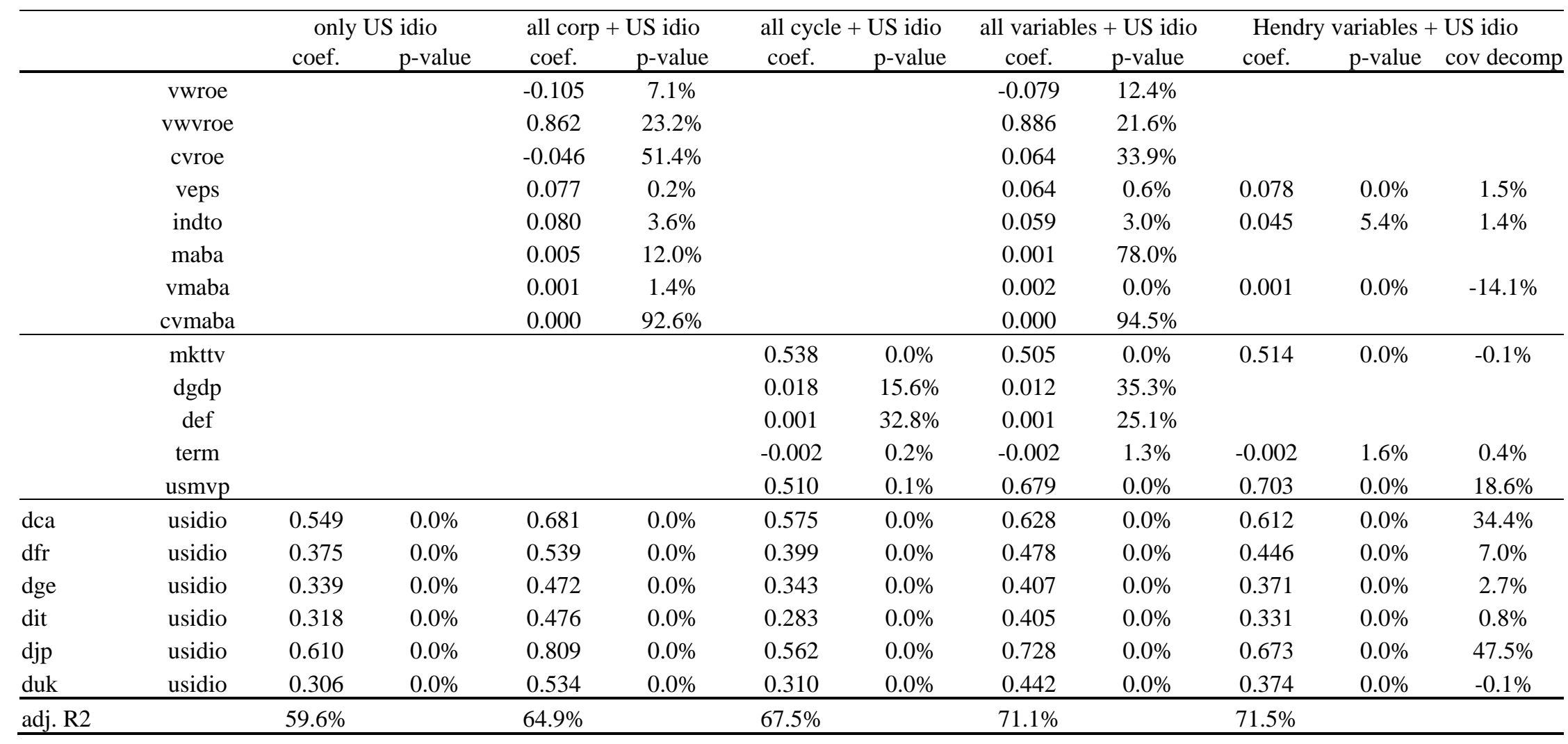


Figure A1. Regime probabilities for G7 countries

This figure reports the smoothed probability of being in regime 2 for the G7 countries other than the U.S., using a regime switching model defined in equations (7) and (8). The model is estimated over sample period $1980-2008$, country by country. The variable $\sigma_{\text {CLMX }}^{2}$ is the aggregate firm level idiosyncratic variance, as defined in equation (2), estimated using daily data.

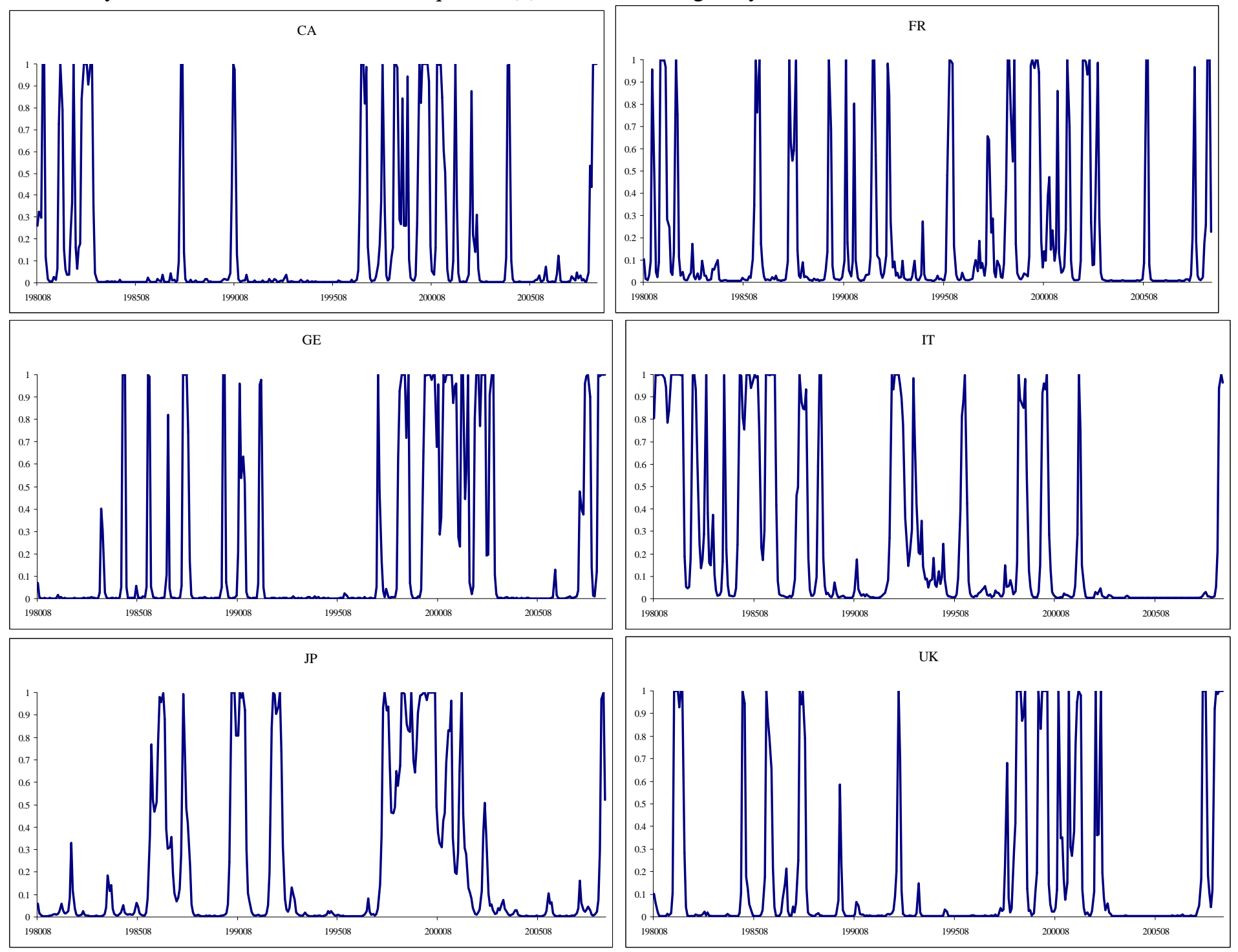

